\title{
EFSUMB Recommendations for Gastrointestinal Ultrasound Part 3: Endorectal, Endoanal and Perineal Ultrasound
}

\section{(ㄷ) (i) $(\mathrm{B})$}

Authors

Dieter Nuernberg1, ${ }^{1}$, Adrian Saftoiu,2, , Ana Paula Barreiros³ ${ }^{3}$ Eike Burmester ${ }^{4}$, Elena Tatiana Ivan², Dirk-André Clevert ${ }^{5}$, Christoph F. Dietrich ${ }^{6}$, Odd Helge Gilja7, Torben Lorentzen ${ }^{8}$, Giovanni Maconi ${ }^{9}$, Ismail Mihmanli10, Christian Pallson Nolsoe ${ }^{11}$, Frank Pfeffer ${ }^{12}$, Søren Rafael Rafaelsen ${ }^{13}$, Zeno Sparchez ${ }^{14}$, Peter Vilmann ${ }^{15}$, jo Erling Riise Waage ${ }^{12}$

Affiliations

1 Medical School Brandenburg Theodor Fontane, Gastroenterology, Neuruppin, Germany

2 Research Center in Gastroenterology and Hepatology, University of Medicine and Pharmacy Craiova, Craiova, Romania

3 Deutsche Stiftung Organtransplantation, Head of Organisation Center Middle, Frankfurt, Germany

4 Department of Internal Medicine/Gastroenterology, Sana-Kliniken Lübeck, Lübeck, Germany

5 Department of Clinical Radiology, Interdisciplinary Ultrasound-Center, University of Munich-Grosshadern Campus, Munich, Germany

6 Caritas-Krankenhaus, Medizinische Klinik 2, Bad Mergentheim, Germany

7 National Centre for Ultrasound in Gastroenterology, Haukeland University Hospital and Department of Clinical Medicine, University of Bergen, Bergen, Norway

8 Ultrasound Section, Division of Surgery, Department of Gastroenterology, Herlev Hospital, University of Copenhagen, Herlev, Denmark

9 Gastroenterology Unit, Department of Biomedical and Clinical Sciences, “L.Sacco” University Hospital, Milan, Italy

10 Istanbul University - Cerrahpasa, Cerrahpasa Medical Faculty, Department of Radiology and ALKA Radyoloji Tani Merkezi, Istanbul, Turkey

11 Ultrasound Section, Division of Surgery, Department of Gastroenterology, Herlev Hospital and Copenhagen Academy for Medical Education and Simulation (CAMES), University of Copenhagen, Denmark

12 Department of Surgery, Haukeland University Hospital and Department of Clinical Medicine, University of Bergen, Bergen, Norway

13 Colorectal Centre of Excellence, Clinical Cancer Centre, University Hospital of Southern Denmark, Vejle, Denmark

14 3rd Medical Department, "luliu Hatieganu" University of Medicine and Pharmacy, Cluj-Napoca, Romania

15 Endoscopy Department, Copenhagen University Hospital Herlev, Herlev, Denmark

* First 2 authors contributed equally to the manuscript.
Key words

endorectal ultrasound, endoanal ultrasound, perineal ultrasound

received $\quad 07.04 .2018$

revised 23.11.2018

accepted $\quad 01.12 .2018$

Bibliography

DOI https://doi.org/10.1055/a-0825-6708

Published online: 2019

Ultrasound Int Open 2019; 5: E34-E51

(c) Georg Thieme Verlag KG Stuttgart · New York

ISSN 2199-7152

Correspondence

Prof. Adrian Saftoiu

Research Center in Gastroenterology and Hepatology

University of Medicine and Pharmacy Craiova

Macinului 1

200640 Craiova, Romania

Tel.: + 40/744/823 355, Fax: + 40/251/310 287

adrian.saftoiu@umfcv.ro

\section{ABSTRACT}

This article represents part 3 of the EFSUMB Recommendations and Guidelines for Gastrointestinal Ultrasound (GIUS). It provides an overview of the examination techniques recommended by experts in the field of endorectal/endoanal ultrasound (ERUS/ EAUS), as well as perineal ultrasound (PNUS). The most important indications are rectal tumors and inflammatory diseases like fistula and abscesses in patients with or without inflammatory bowel disease (IBD). PNUS sometimes is more flexible and convenient compared to ERUS. However, the technique of ERUS is quite well established, especially for the staging of rectal cancer. EAUS also gained ground in the evaluation of perianal diseases like fistulas, abscesses and incontinence. For the staging of perirectal tumors, the use of PNUS in addition to conventional ERUS could be recommended. For the staging of anal carcinomas, PNUS can be a good option because of the higher resolution. Both ERUS and PNUS are considered excellent guidance methods for invasive interventions, such as the drainage of fluids or targeted biopsy of tissue lesions. For abscess detection and evaluation, contrast-enhanced ultrasound (CEUS) also helps in therapy planning. 


\section{Introduction}

This article represents part 3 of the European Federation of Societies for Ultrasound in Medicine and Biology (EFSUMB) Recommendations and Guidelines for Gastrointestinal Ultrasound (GIUS). It provides an overview of the examination techniques recommended by experts in the field for EndoRectal (ERUS), EndoAnal UltraSound (EAUS) and PeriNeal UltraSound (PNUS). Concerning ERUS, various other terms are used in the literature for the same technique, including transrectal ultrasound (TRUS), anorectal ultrasound (ARUS), and endoanorectal ultrasound (EARUS). Due to standardization of the guideline, we preferred the arbitrary distinction between ERUS and EAUS, with these being the abbreviations used in the manuscript.

Part 3 of the Guidelines for Gastrolntestinal Ultrasound (GIUS) provides an overview of the examination of the anorectum and the perineal region with the techniques of ERUS, EAUS, as well as PNUS. PNUS is a method characterized as effective, inexpensive, safe, available everywhere and associated with minimal pain, mostly because it is noninvasive and does not need a special application set or probe. However, it is also a rarely used diagnostic tool in daily practice. In contrast, the ERUS technique is quite well established, especially for the staging of rectal cancer. EAUS has also gained ground in the evaluation of anorectal diseases like fistulas, abscesses and incontinence.

For each recommendation, levels of evidence (LoE) and grades of recommendation (GoR) were included to evaluate the clinical role in various applications. These were assigned according to the criteria of the Oxford Centre for Evidence-Based Medicine (http:// www.cebm.net/oxford-centre-evidencebased-medicine-levels-evidence-march-2009/). The manuscript and voting have been finalized by e-mail communication. A total number of 22 figures with 40 individual images accompany this manuscript.

\section{Endorectal Ultrasound}

\section{Anatomy and sonoanatomy}

Endorectal ultrasound (ERUS) provides high-resolution examination of the rectal wall with clear visualization of its 5 layers closely reproducing the anatomic layers. The innermost hyperechoic line is the resulting interface between the transducer/water-filled balloon and the superficial mucosa. A hypoechoic layer follows, representing the mucosa and muscularis mucosa. The second hyperechoic submucosal layer is followed by another hypoechoic layer which is the muscularis propria. Lastly, another hyperechoic layer represents the interface between the rectal wall and surrounding fatty tissue, or represents the serosa in the peritoneal part of the rectum. Further differentiation of the rectal wall layers is possible with high-frequency (HF) transducers which are able to separate the inner circular and the external longitudinal layers of the muscularis propria. When staging rectal tumors, i. e., located up to $15 \mathrm{~cm}$ from the anal verge, ERUS clearly depicts the iso- or hypoechoic invasion of the tumor which disrupts the normal echo-layer pattern. For orientation, anterior anatomic structures (prostate, seminal vesicles, urinary bladder, vagina and uterus) should be identified. With radial scanners these are usually placed at the 12 o'clock position on the ultrasound image. Surrounding lymph nodes are recognized as round or oval hypoechoic structures as compared to the perirectal tissue [1,2].

\section{Examination technique}

For an accurate ERUS examination, the rectum needs to be properly cleaned to avoid artifacts from residual stool. For this purpose, a cleansing enema is routinely given before the procedure, although a full-bowel preparation may be used to optimize imaging. The examination is performed with the patient in the left lateral decubitus or lithotomy (gynecological) position. Sedation is usually not necessary as it is a well-tolerated procedure [3]. A digital rectal examination and at least a rectosigmoidoscopy should precede ERUS examination, especially for tumor staging, in order to describe the size and location of the lesion. A thorough examination of the tumor by flexible sigmoidoscopy prior to ERUS will facilitate a targeted approach to areas of suspected invasion.

Either rigid blind rectal probes or flexible echoendoscopes enabling radial or linear scanning may be used, with ultrasound frequencies ranging between $5 \mathrm{MHz}$ and $15 \mathrm{MHz}$. End-fire probes like those used for prostate examinations may also be used, especially for proximal tumors and lymph node evaluation. These are incrementally adjusted according to the desired resolution and depth of penetration [1]. Rigid blind rectal probes are commonly used in clinical practice due to their lower costs and availability. Flexible echoendoscopes may be advanced under visual control up to the level of the tumor and are able to pass through narrower lumens of stenosing tumors. Comparative studies between the 2 types of devices are currently limited and have shown contradictory results for rectal cancer staging [4-6]. Both types of probes (rigid and flexible) do have the possibility of examining the iliac lymph nodes at about 20-25 cm from the anal verge. Malignant invasion at this level indicates an $\mathrm{M} 1$ stage which consequently alters patient management [7]. For interventional procedures, a linear echoendoscope or an end-fire probe is necessary to allow needle passage under direct ultrasound visualization [1,2]. High-resolution miniprobes which can be passed through the working channel of standard colonoscopes are also an option, because they are able to pass obstructive tumors. On the other hand, the limited in-depth penetration makes these probes less convenient for staging more advanced cancers [8].

For rectal cancer examination, the ERUS rigid probe/flexible echoendoscope should be advanced beyond the targeted lesion, whenever possible. Acoustic coupling for optimal imaging is achieved by successive water instillation and deflation of air. A water-filled balloon covering the transducer may also be used. It must be carefully adjusted to avoid tumor compression and false findings [9]. Ultrasound examination is performed during slow withdrawal down to the level of the anal verge. The maximum depth of tumor invasion into the rectal wall should be noted as well as involvement of surrounding structures. Any peri-tumoral lymph nodes should be characterized by their size, shape and echo-structure. Ultrasound classification follows the international TNM staging system, adding the 'u' prefix for recognition (- Fig. 1) [1, 2].

Recommendation 1: Either rigid probes or flexible echoendoscopes can be used for the evaluation of rectal lesions, depending on availability and local expertise. LoE 1 b, GoR B (For 15, Abstain 0, Against 0) 


\section{Special techniques}

The use of contrast enhancement has brought significant improvements in ultrasound examination protocols and better characterization of lesions based on their perfusion pattern. With the use of second-generation microbubble contrast agents and recent technology improvements, even low-velocity flow micro-vessels can be detected. Additional post-processing software applications provide quantitative measurements of vascularization based on time-intensity curve analysis, generating several objective parameters as a measure of blood flow and volume in a selected region of interest. Consequently, multiple clinical indications have been described for contrast-enhanced ultrasound (CEUS) and also further research directions, including the study of tumor angiogenesis $[10,11]$.

Contrast enhancement during EUS (CE-EUS) has been used mainly for differentiating pancreatic lesions based on their vascular pattern [11], while data regarding its use in colorectal lesions is currently limited. Only a couple of studies have reported the possibility of using CE-EUS for the evaluation of rectal tumor vascularity ( $\mathbf{F i g} .2$ ). These have shown different perfusion patterns between rectal cancers, rectal adenomas and inflammatory lesions [12]. Likewise, weak correlations have been described between the parameters resulting from time-intensity curve analysis of the CEEUS sequences, such as enhanced peak intensity and microvascular density with histological grading $[13,14]$. Based on further research, CE-EUS might offer valuable functional information on tumor angiogenesis with a potential impact on the prognosis and management of rectal cancer patients.

Ultrasound-based elastography assessment is a relatively novel approach to rectal tumor evaluation. The method is already used in clinical practice for other organs $[15,16]$. The principle of ultrasound elastography assessment of rectal tumors is the change in tumor hardness caused by malignant transformation. There are multiple elastography methods, but to date only strain elastography (quasi static elastography) has been tested for the endoluminal staging of rectal tumors, although point shear wave elastography has shown promise using the transperineal approach $[17,18]$. Strain elastography enables visualization and semi-quantification of tissue elasticity by generating a color-coded map which is superimposed onto a B-mode image. The subsequent elastography assessment can be performed by a semiquantitative strain ratio measurement, or by subjective assessment of the elastogram using a continuous visual analog score (VAS) and/or a categorical W-score
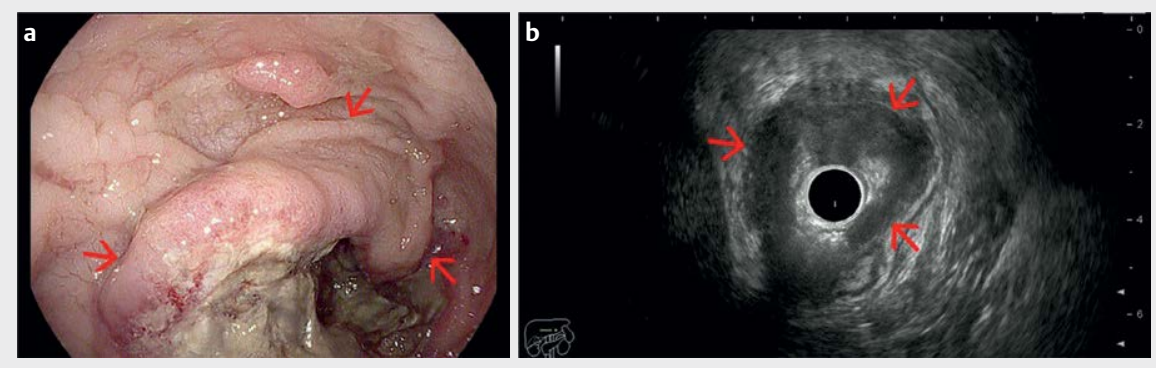

-Fig. 1 a Biopsy proven circumferential rectal adenocarcinoma visualized endoscopically at $8 \mathrm{~cm}$ from the anal verge (red arrows). b Radial endorectal ultrasound (ERUS) showed the hypoechoic mass (red arrows) extending beyond the muscularis propria in the perirectal fat (uT3) (courtesy of Adrian Săftoiu, Elena Tatiana Ivan).

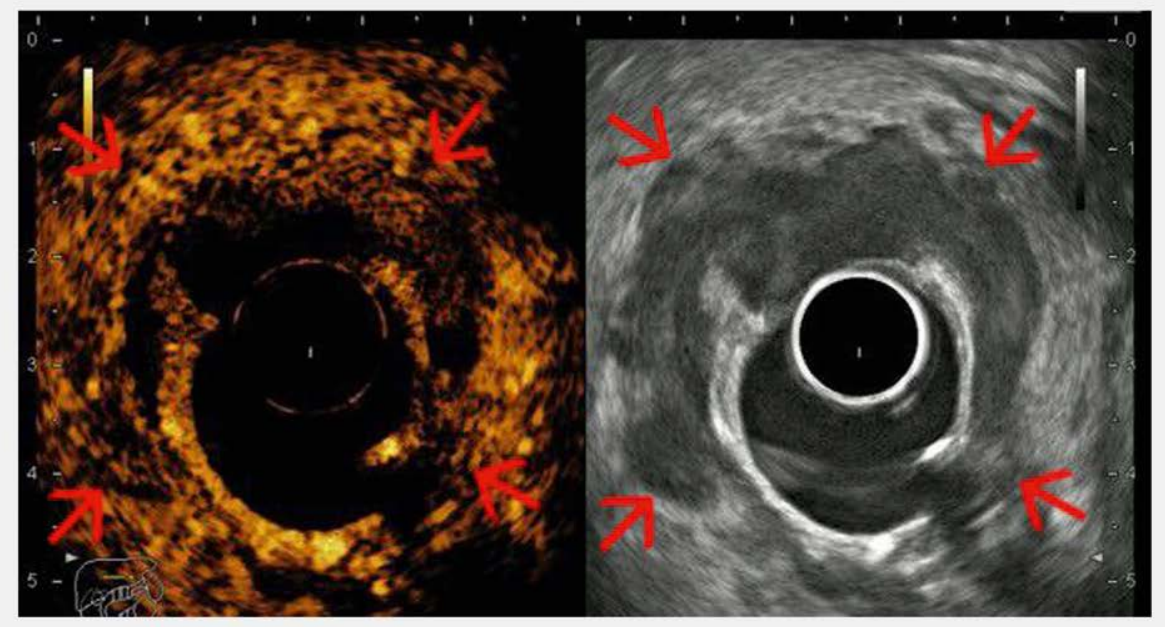

-Fig. 2 Contrast-enhanced radial endorectal ultrasound (ERUS) showing a hyperenhanced (hypervascular) semi-circumferential rectal tumor (red arrows), with an area of un-enhanced central necrosis (courtesy of Adrian Săftoiu, Elena Tatiana Ivan). 


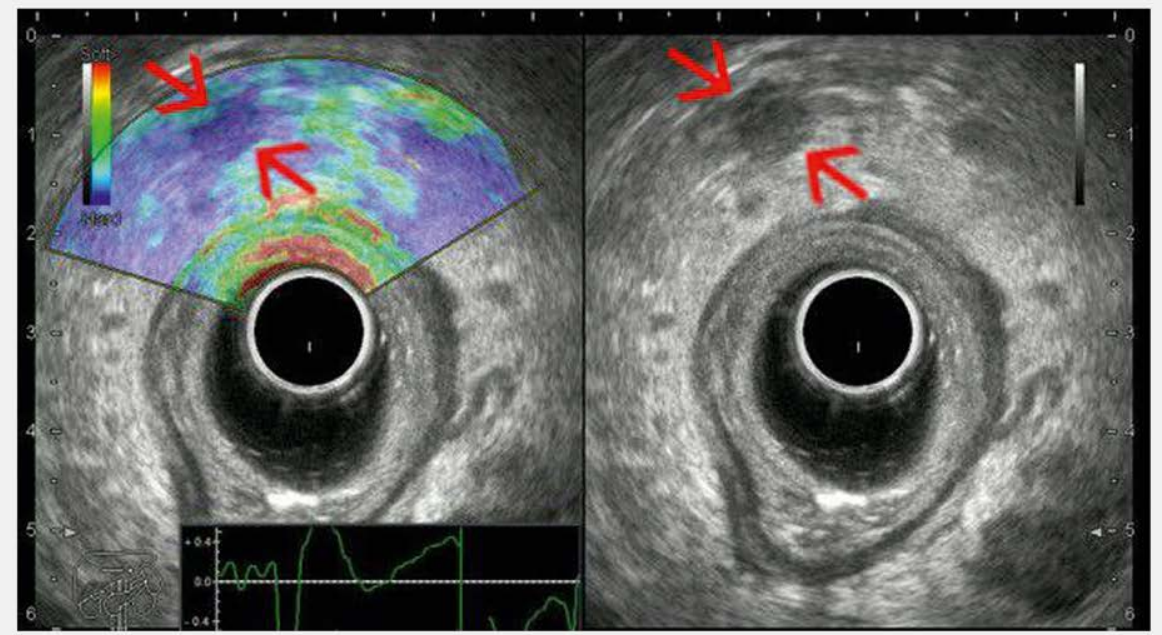

- Fig. 3 Radial endorectal ultrasound (ERUS) elastography showing a hard (low strain) perirectal lymph node (red arrows) in a patient with concomitant rectal adenocarcinoma. A balloon surrounding the transducer is inflated with water to improve acoustic coupling with the rectal wall (courtesy of Adrian Săftoiu, Elena Tatiana Ivan).
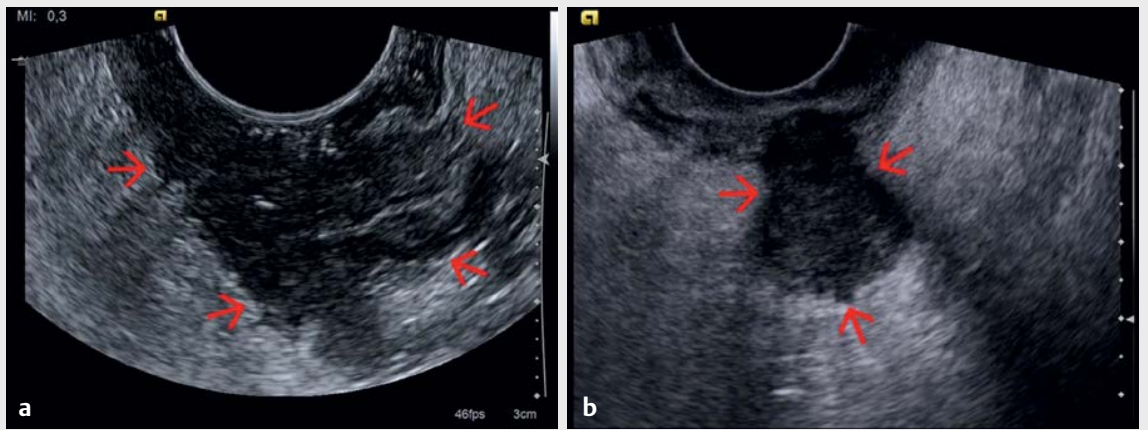

Fig. 4 ab Hypoechoic tumor mass (red arrows) extending beyond the muscularis propria layer (T3), examined with a rigid end-fire probe (courtesy of Søren Rafaelsen).

$[19,20]$. It has been shown that ERUS elastography is able to differentiate adenomas from adenocarcinomas with a higher accuracy as compared to ERUS and magnetic resonance imaging (MRI) [21]. The method cannot be used to further improve the differentiation of T2-T4 stages, but a combined elastography and ERUS algorithm has been shown to significantly improve the identification of tumors eligible for local resection compared to standard clinical evaluation with ERUS and MRI [22]. ERUS elastography can be used for the evaluation of perirectal lymph nodes ( $\bullet$ Fig. 3 ), although no systematic studies have been published to the best of our knowledge.

\section{Indications}

\section{Diagnosis and staging of rectal tumors}

Rectal cancer is staged according to the $8^{\text {th }}$ AJCC Staging Manual for TNM classification [23]. MRI is considered mandatory and the first-choice technique for the staging and re-staging of advanced rectal cancer, as mentioned in the radiological guidelines [24]. Nevertheless, ERUS is regarded as a fast, safe and accurate imaging method for the diagnosis and staging of rectal cancer, complementing the results of MRI. ERUS has also been used for more than 3 decades with the main indications being the assessment of the local spread of rectal tumors at initial diagnosis ( $\mathrm{T}$ and $\mathrm{N}$ staging) in correlation to the TNM classification and during patient follow-up $[1,2]$. As a consequence of the staging procedure, ERUS is able to indicate the treatment pathway for patients to follow-up in both early and locally advanced stages ( $\bullet$ Fig. $\mathbf{4}, \mathbf{5}$ ) by determining the type of primary resection and whether neoadjuvant chemoradiation is necessary.

Studies available from the literature have reported very good performance of ERUS regarding the pre-therapeutic assessment of the depth of tumor invasion, with sensitivities and specificities ranging between $80-96 \%$, and $80-98 \%$, respectively, as shown by meta-analyses $[25,26]$. ERUS is the best documented examination for classifying early rectal lesions [27], either confined to the mucosa (sensitivity and specificity 97\%) which may be referred for endoscopic resection ( $\boldsymbol{F}$ Fig. $\mathbf{6}, \mathbf{7}$ ) [28] or submucosal cancers (ac- 

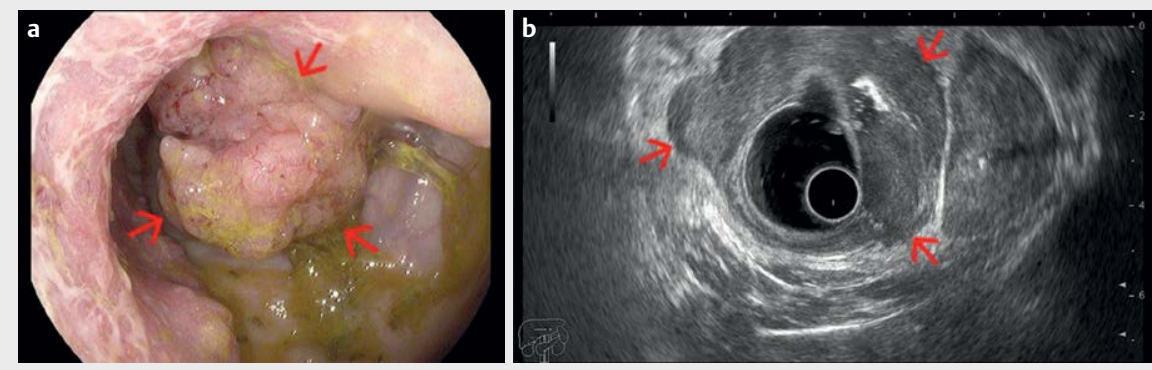

- Fig. 5 a Advanced rectal tumor visualized endoscopically as a large vegetating tumor. b Radial endorectal ultrasound (ERUS) delineates the tumor as a hypoechoic mass extending beyond the muscularis propria (red arrows) but with clear delimitation from the prostate (T3) (courtesy of Adrian Săftoiu, Elena Tatiana Ivan).
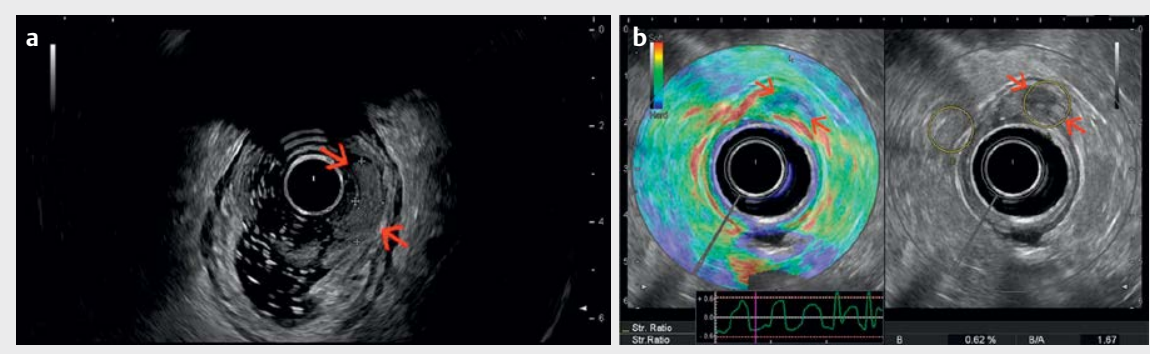

- Fig. 6 a Histological proven, endoscopically resected T1 rectal adenocarcinoma (red arrows). b Early rectal adenocarcinoma (uT1) limited to the submucosa, visualized by endorectal strain elastography as a hard (low strain) mass at 12 to 1 o'clock (courtesy of Eike Burmester, Frank Pfeffer).

curacy 95\%) suitable for transanal endoscopic microsurgery in selected cases (pT1sm1) [29, 30]. Due to its limited in-depth ultrasound penetration, ERUS is less accurate in depicting the mesorectal fascia, an important predictor of local recurrence which is better evaluated by MRI [27]. Especially for the staging of early tumors considered for local excision, ERUS should be used additionally to MRI due to its superior diagnostic performance for differentiating $\mathrm{T} 1$ from T2 tumors ( $\mathbf{F i g . ~} \mathbf{6 ,} \mathbf{7}$ ) [23, 28].

There is a learning curve for practicing ERUS examination $[31,32]$ and the accuracy is at a stable level only after 50 scans [33]. Consequently, results from a multicenter study including $7096 \mathrm{pa}-$ tients from more than 300 hospitals, which were mostly centers with a low case load volume, did not achieve the high accuracy reported in the literature [34].

It is difficult to differentiate between benign and malignant lymph nodes using ERUS [35], even for experienced users. Moderate sensitivities (57-73\%) and specificities (76-80\%) have been reported by several meta-analyses [26,36-38]. However, none of the currently available imaging methods (MRI and CT) can provide more reliable information on lymph node status [38]. ERUS-guided fine needle aspiration (FNA) enables pathology confirmation of suspicious perirectal lymph nodes, but it is rarely performed since the needle must pass the primary tumor. Also, a real impact on patient management as compared to ERUS alone has not been demonstrated [9]. ERUS-FNA biopsy seems highly accurate for the diagnosis of colorectal cancer recurrences [39], as it may impact therapeutic decisions [40].
Conventional ERUS is not useful in the re-staging after neoadjuvant chemoradiotherapy $[41,42]$. Even for experienced endosonographers, the inflammation and fibrosis induced by radiotherapy are difficult to differentiate from malignant tissue, resulting in a low diagnostic accuracy. Sonographic definition and comparison with previous ultrasound findings for the lesion can be advised in patients undergoing neoadjuvant chemoradiotherapy [43].

Recommendation 2: ERUS can be used in the pre-therapeutic staging of rectal cancer, especially in early rectal tumors with an indication for local resection, due to its ability to better differentiate T1 and T2 stages. LoE 1b, GoR B (For 15, Abstain 0, Against 0)

Recommendation 3: ERUS alone cannot currently be recommended for assessing lymph node involvement in rectal cancer patients, due to its moderate accuracy for differential diagnosis between benign and malignant lymph nodes. LoE 1a, GoR A (For 12, Abstain 1, Against 2)

Recommendation 4: Proper training is recommended before practicing ERUS for the staging of rectal cancer. LoE $2 \mathbf{b}$, GoR B (For 15, Abstain 0, Against 0)

Recommendation 5: ERUS-FNA biopsy can be recommended for diagnosing perirectal lesions in patients with a history of colorectal cancer, as it may impact therapeutic decisions. $\mathbf{L O E} \mathbf{2} \mathbf{b}$,

\section{GoR B (For 15, Abstain 0, Against 0)}

\section{Diagnostic and therapeutic interventions}

ERUS-guided intervention by means of biopsy or drainage can be performed with a rigid ultrasound probe as well as with flexible ech- 


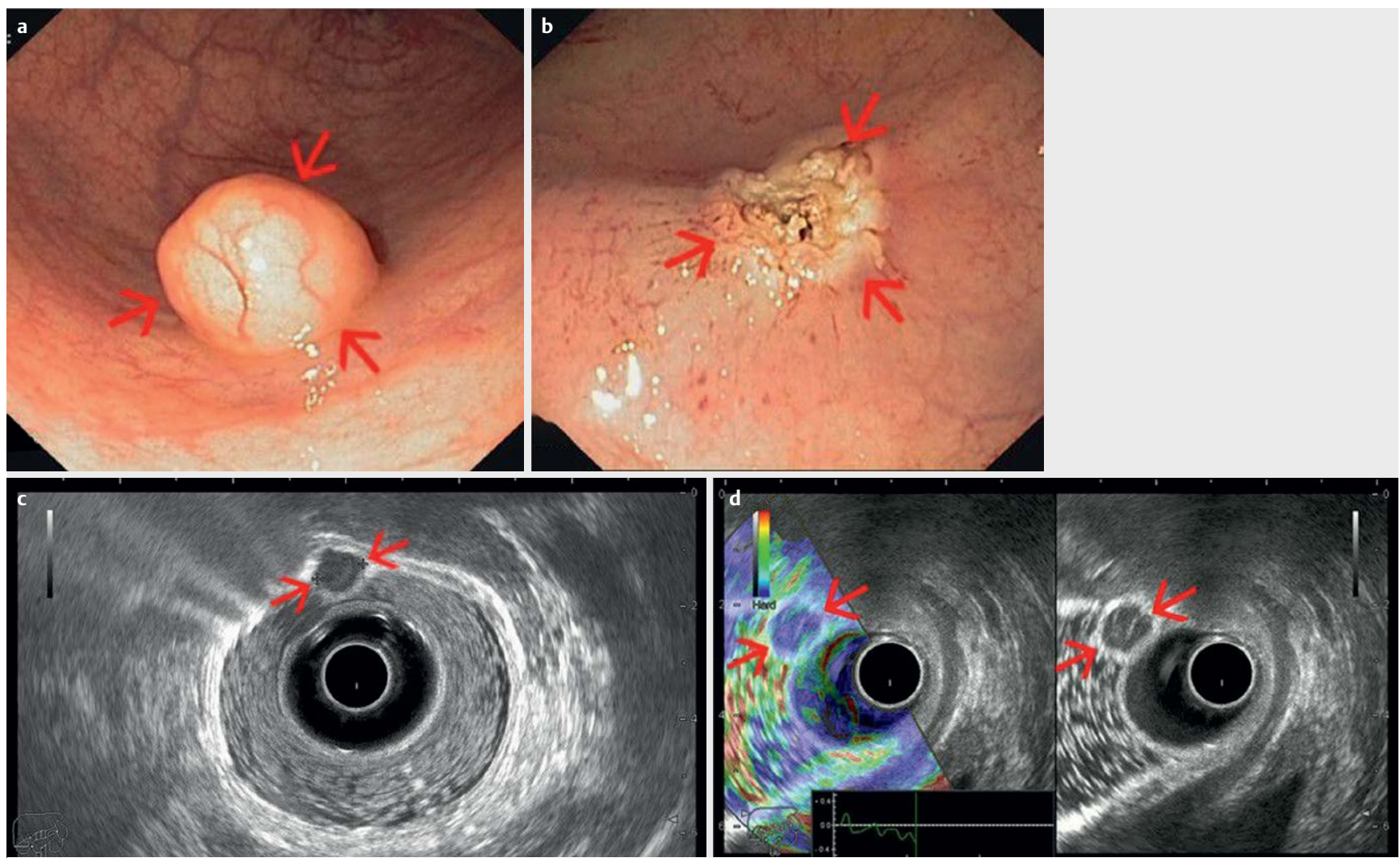

- Fig. 7 ab Early rectal neuroendocrine tumor visualized endoscopically as a small mass with normal appearing mucosa, completely resected by endoscopic mucosal resection. cd Radial endorectal ultrasound (ERUS) delineates the small tumor (red arrows) as a hypoechoic mass, hard by elastography, limited to the mucosa, with clear demarcation from the submucosa and muscularis propria ( $\mathrm{T} 1$ ). Water has been instilled in the balloon covering the ultrasound transducer, as well as in the rectum for better acoustic coupling between the transducer and rectal structures (courtesy of Adrian Săftoiu, Elena Tatiana Ivan).

oendoscopes. These are currently considered to be fast, safe, and accurate techniques.

The rigid ultrasound probe with an end-fire design or linear EUS scopes are optimal for ERUS interventions and can in most cases visualize the entire rectum, including perirectal structures. By using a dedicated needle guide mounted on the end-fire probe, this technique enables precise puncture of most rectal or perirectal targets seen on ERUS. ERUS-guided biopsy of rectal masses is an important supplement to conventional endoscopic biopsy if the latter technique does not provide the final diagnosis. Indications are staging of rectal cancer or suspicion of local recurrence. In these cases, ERUS-guided biopsy of a rectal mass with a 1.2-mm needle (18-gauge automatic or semi-automatic biopsy systems) can provide a deep tissue sample that often results in a final histologic diagnosis. In addition, ERUS-guided biopsy is an obvious technique to provide histological or cytological information about enlarged lymph nodes or other suspicious perirectal masses.

ERUS-guided drainage of deep pelvis abscesses or other fluid collections is a safe approach and effective treatment in cases where the transabdominal percutaneous access cannot be utilized because of overlying structures. The technique has been evaluated in several series together with alternative access techniques such as the transvaginal, transgluteal, and transperineal techniques [44]. Smaller abscesses can often be treated with needle aspiration fol- lowed by saline irrigation, whereas larger abscesses may require continuous drainage through a catheter, which can be inserted using the Seldinger technique. A pre-procedure CT or MRI examination of the lower abdomen is recommended to visualize the location and size of the abscess in order to optimize drainage.

Recommendation 6: ERUS represents an effective guidance method for diagnostic and therapeutic interventions from the rectal side. LoE 4, GoR C (For 15, Abstain 0, Against 0)

\section{EndoAnal UltraSound}

\section{Introduction}

Evaluation of the anal canal can be performed with different imaging modalities, such as US, MRI, CT and PET-CT [1]. With respect to both ultrasound and MRI, scanning can be carried out with an endoanal approach (i. e., so-called EAUS) and endorectal coil MRI, respectively. For clinical use, EAUS has by far the highest resolution, both spatial and temporal, with visualization of submillimeter structures and real-time scanning. 

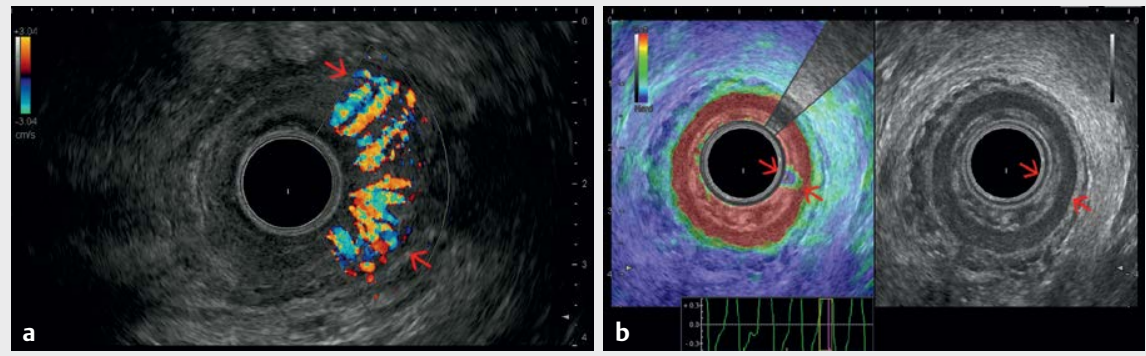

- Fig. 8 a Color flow imaging showing the Doppler appearance of a hypervascular inflammed anal region. $\mathbf{b}$ Endoanal ultrasound (EAUS) with a 360-degree radial transducer showing the muscular layers of the anal canal (red arrows), as well as the soft appearance of an inflammed anal sphincter region (courtesy of Christoph F. Dietrich).

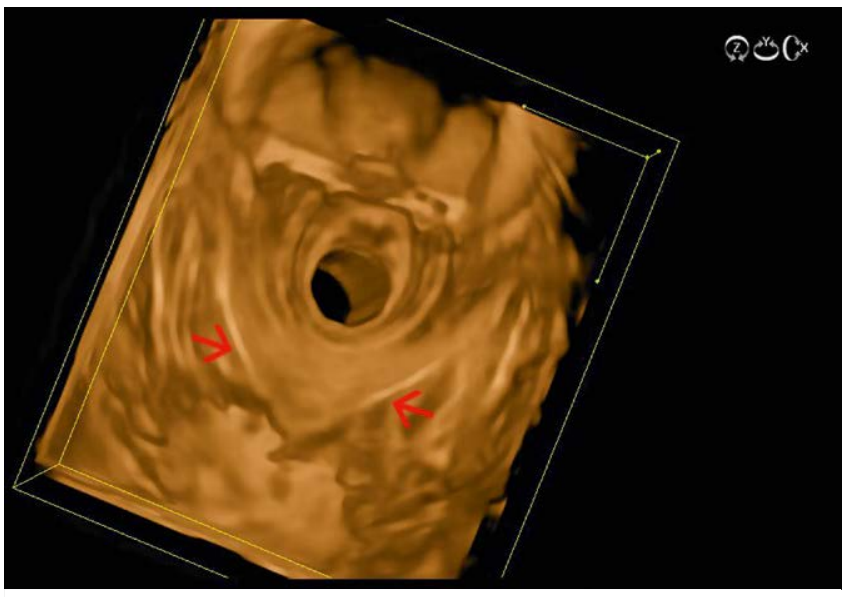

-Fig. 9 The U-shaped puborectalis muscle visualized with 3D radial endoanal ultrasound (red arrows) (courtesy of Eike Burmester).

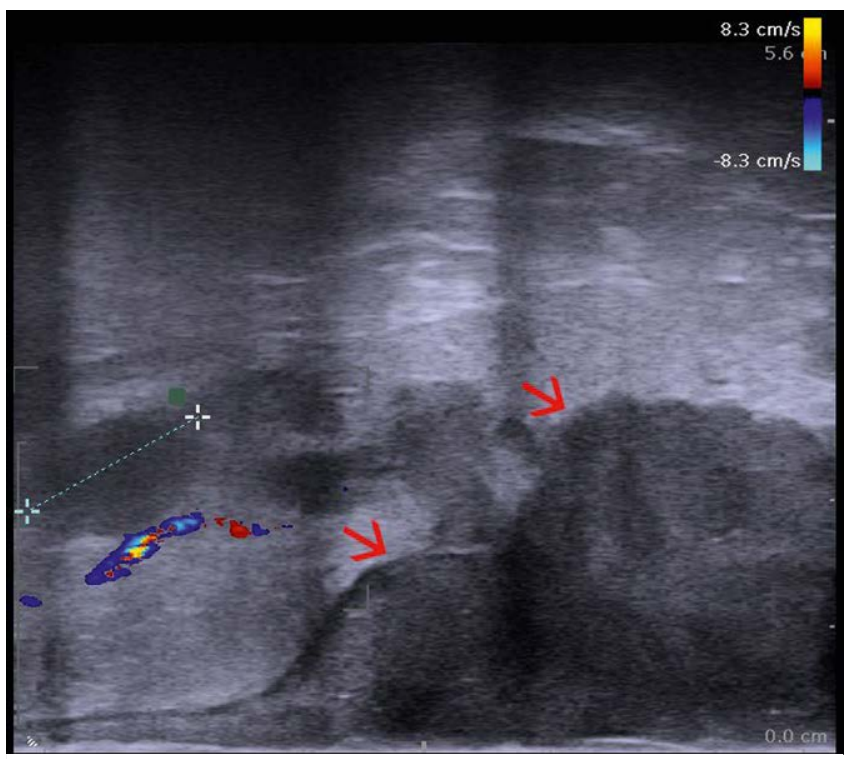

Fig. 10 Linear endoanal ultrasound (EAUS) showing the tumor (red arrows) extension from the anodermal junction, as well as thickness, with an oval, hypoechoic, well demarcated lymph node of $15 \mathrm{~mm}$ in the perirectal fat shown between markers (UT3N1) (courtesy of Christian Nolsøe, Torben Lorentzen).

\section{Anatomy, sonoanatomy, and examination techniques}

EAUS is performed with dedicated 5-12 MHz electronic and mechanical endoprobes of either radial, linear or curved array transducers. In the hands of an experienced user, EAUS represents an indispensable tool in the evaluation of both benign and malignant anal diseases. All ultrasound techniques, including color Doppler ( $\vee$ Fig. 8a), contrast enhancement and elastography ( $\vee$ Fig. 8b), can be utilized, based on the current software embedded in ultrasound scanners.

The 360-degree transducer may be capable of generating 3D rendered images to facilitate better visualization of the volumetric appearance of the normal anatomy and abnormal findings ( $\triangleright$ Fig. 9). Thus, 3D EAUS has already been shown to improve the staging of anal cancer, including recurrent anal cancer, as compared with 2D techniques $[45,46]$. Another option is an endotransducer with a linear array of $5 \mathrm{~cm}$ or longer, mounted parallel to the long axis of the transducer in order to provide scanning planes perpendicular to the transducer's long axis with a broad field of view ( $>$ Fig. 10 ). The scanning technique implies manual rotation of the transducer 360 degrees in a clockwise direction to perform an round-trip anal examination. Rotating the transducer clockwise from 12-3 will thus create scan planes turning from the sagittal to the median plane, through oblique fields of view, to the coronal plane. The rotating movement is continued until the image plane is back a 12 o'clock pointing anteriorly. The linear array transducer is also useful for US-guided intervention (biopsy, needle puncture, or catheter drainage). Furthermore, hydrogen peroxide or a few drops of an ultrasound contrast agent (SonoVue) may enhance US visualization of fistulas.

The ultrasound anatomy of the anal canal is dominated by the change in arrangement of the muscular layers of the wall which is made up solely of the concentric muscles of the internal (IAS) and external anal sphincter (EAS). The anal canal constitutes the distal $2.5-5 \mathrm{~cm}$ of the bowel system and is divided into 3 levels relating to the sphincter muscles. The anal canal also represents the transition between the cylindrical mucosal lining in the rectum and the squamous cell lining of the skin. In the cranial third, ultrasound clearly visualizes the EAS continuing into and forming the $\mathrm{U}$-shaped puborectalis muscle, keeping in mind that the anterior part of the EAS is generally shorter in women at this level. In the middle third, the IAS is often visualized distinctly as an inner echo-poor (hypo- 

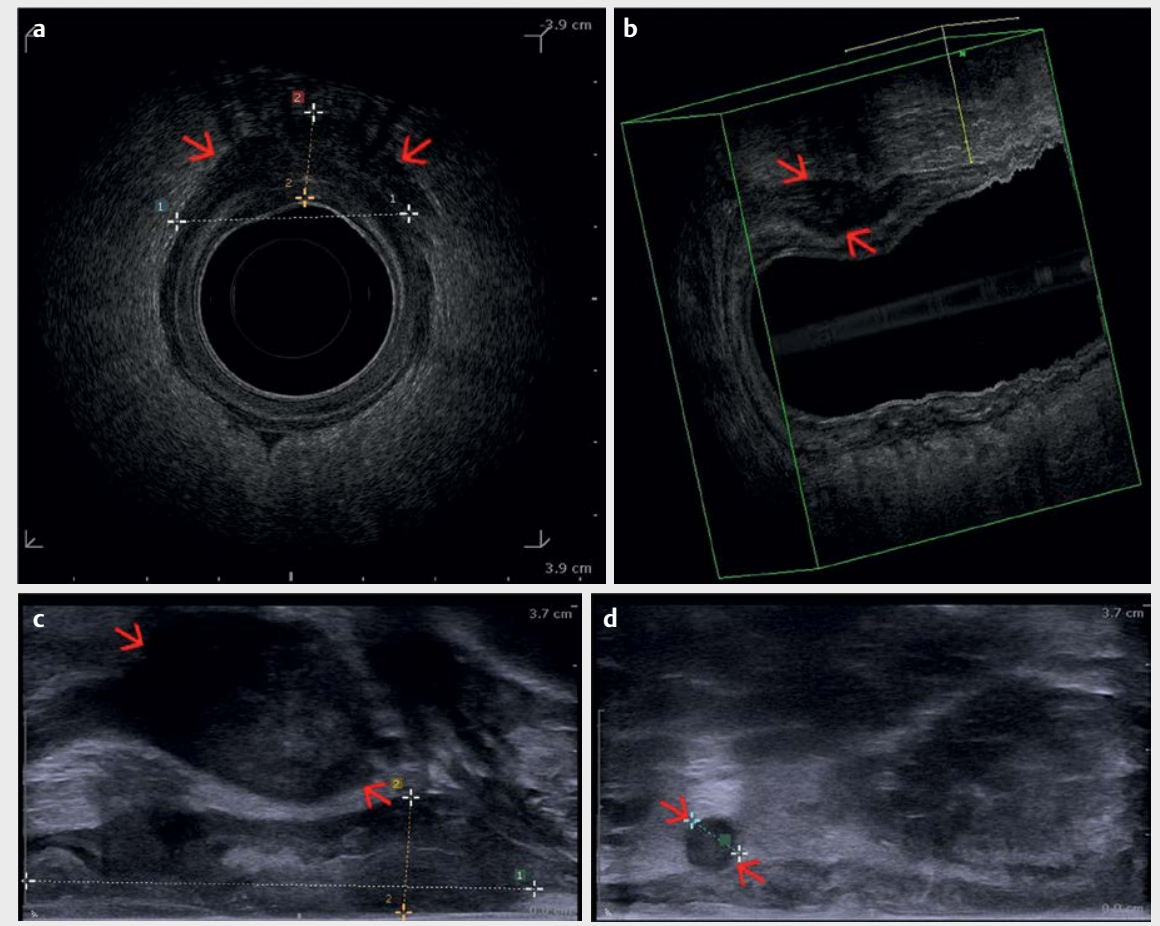

- Fig. 11 a Radial endoanal ultrasound (EAUS) of an anal carcinoma (red arrows) extending beyond the anal sphincter shown between markers (UT3). b 3D reconstruction of the anal canal, including the tumor (red arrows), which can be precisely measured. c Linear endoanal ultrasound (EAUS) showing the tumor extension (red arrows) from the anodermal junction, as well as thickness. $\mathbf{d}$ Round, hypoechoic, well demarcated lymph node (red arrows) in the perirectal fat shown between markers (uN1) (courtesy of Christian Nolsøe, Torben Lorentzen).

echoic) layer clearly demarcated against the outer, sometimes more diffusely visualized, EAS. In the lower anal canal, the usually more hyperechoic EAS continues distally to the IAS into its end point at the level of the anus. Thus, the EAS is the outermost muscle of the distal anal canal and the IAS is discontinuous at this level. The echo-rich EAS is the voluntary muscle used to control defecation whereas the echo-poor IAS is not under conscious control. The thickness of the IAS differs between 2 and $4 \mathrm{~mm}$ and enlarges with age; the EAS has a thickness of $10-13 \mathrm{~mm}$. In women the ventral part of the EAS is smaller than the dorsal part [47].

\section{Indications}

\section{Anal cancer}

Anal cancer is staged according to the $8^{\text {th }}$ AJCC Staging Manual for TNM classification [23]. Thus, EAUS is utilized in the locoregional staging of anal carcinoma before radio-chemotherapy or surgery and during the course of follow-up, if clinical examination is impaired due to pain or other imaging modalities are equivocal [48-50]. In addition to endoluminal evaluation, a surface ultrasound examination of inguinal lymph nodes using a high-resolution $6-10 \mathrm{MHz}$ linear array is performed to supplement the locoregional $\mathrm{N}$ stage evaluation [51].

EAUS and MRI are comparable in the assessment of local tumor extension [51,52] and both are recommended in international oncology guidelines [48]. The scientific literature comparing different imaging modalities or imaging with pathological specimens is very limited with only 2 prospective studies available [51, 53]. Only a few older studies comparing endoanal with clinical follow-up and outcome are available $[54,55]$. EAUS was thus reported to be superior to MRI for the detection of small superficial tumors with a sensitivity of $100 \%$ vs. $88.9 \%$, respectively. Nevertheless, MRI may be needed for supplementary $\mathrm{N}$ staging as regional lymph nodes are outside the field of view for EAUS [51].

The optimal transducer for endoanal staging depends on the experience of the examiner. During endoanal cancer staging, any tumor should be described in the ultrasound scanning report with the largest dimension in terms of craniocaudal length, thickness, and extension in the clockwise direction plus the notion of the most caudal extension relative to the anodermal junction ( $\vee$ Fig. 11a-c).

Lymph nodes visualized in the perirectal space with a round, echo-poor appearance are considered malignant ( $\triangleright$ Fig. 11d), whereas lymph nodes in the inguinal regions should be biopsied if suspicious on ultrasound or further characterized with PET-CT before finally considered malignant $[48,49]$.

Recommendation 7: EAUS is recommended for locoregional T staging of anal cancer. LoE 2b, GoR B (For 14, Abstain 1, Against 0)

Recommendation 8: EAUS can be recommended for locoregional $\mathrm{N}$ staging of anal cancer as a complement to other diagnostic tests such as PET-CT and MRI. LoE 5, GoR C (For 15, Abstain 0, Against 0)

\section{Anal fistula}

EAUS is recommended in patients with suspected or proven anal fistulas since this technique has been shown to be superior to clin- 


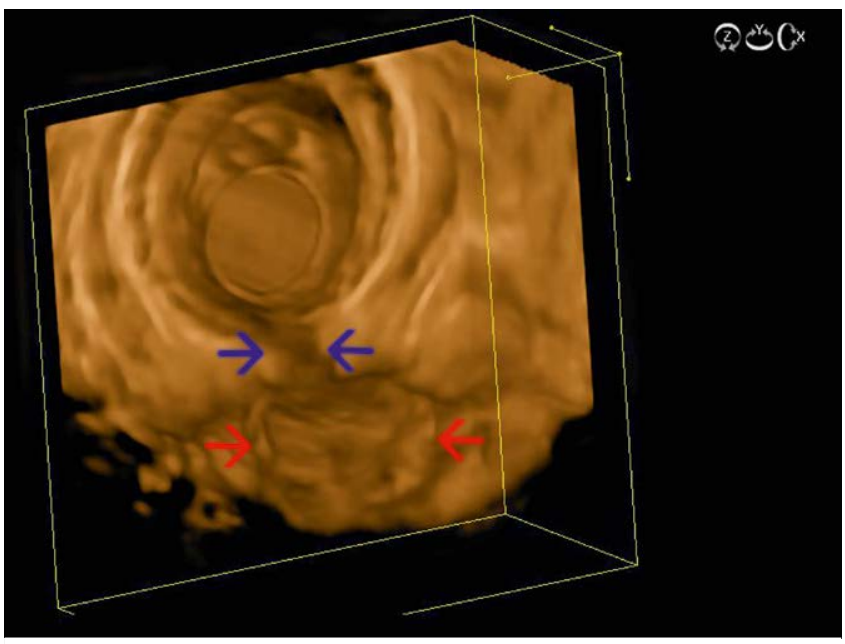

Fig. 12 Endoanal ultrasound (EAUS) with 3D reconstructions, showing a cryptoglandular fistula (blue arrows) with a dorsal abscess in between red arrows (courtesy of Eike Burmester).

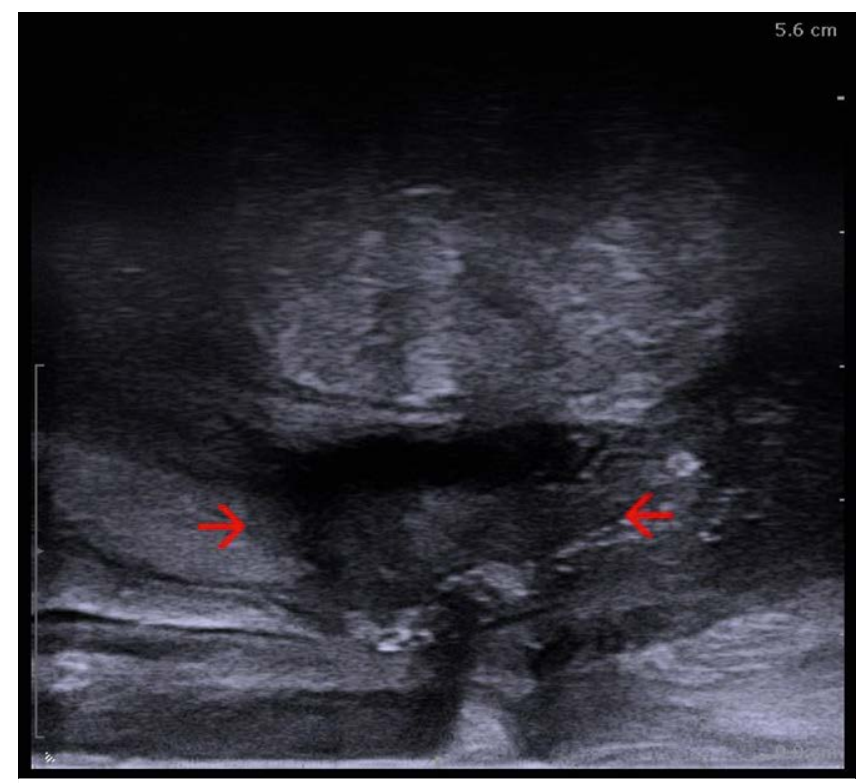

- Fig. 13 Recto-vaginal fistula containing fluid and gas (red arrows), visualized through a transrectal approach with a linear endoanal ultrasound (EAUS) probe (courtesy of Christian Nolsøe, Torben Lorentzen).

ical examination alone in order to delineate the site of internal openings, anatomical relation to sphincters, extensions and septic complications, like abscesses ( $\mathbf{F i g}$. 12,13) [56, 57]. Furthermore, several randomized prospective studies have also shown that EAUS could be successfully used to guide medical and surgical therapy of perianal fistulizing Crohn's disease ( Crohn's disease, fistulas are located in the perianal region in over $50 \%$ of cases. Most of them are complex, with EAUS influencing patient management in $86 \%$ of patients [62]. Anal fistulas should be described according to the Park's classification (intersphincteric, transsphincteric, suprasphincteric and extrasphincteric fistulas) ( $\triangleright$ Fig. 15a-c, $>$ Fig. 16) [63].

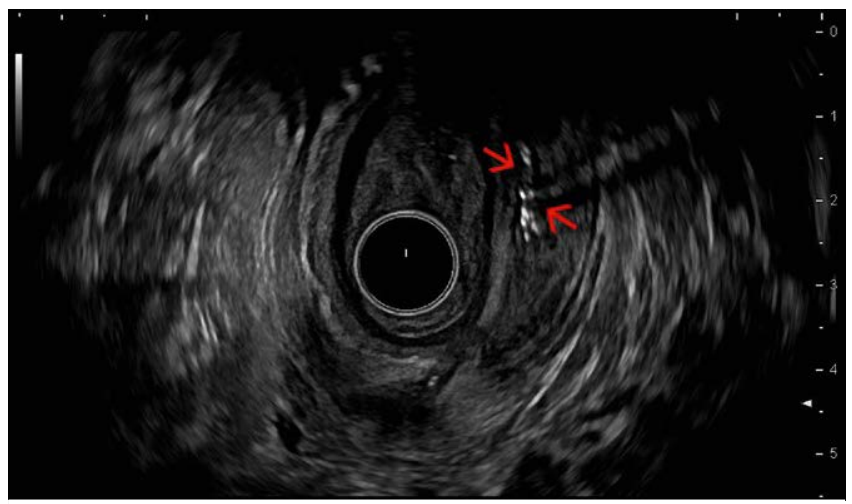

Fig. 14 Echorich, air-bubble filled supra-sphincteric Crohn's fistula (red arrows) visualized with radial endoanal ultrasound (EAUS) at 2-3 and $6 o^{\prime}$ 'clock position (courtesy of Eike Burmester).

Several comparative studies have shown almost identical performance of EAUS and MRI in the detection of anal fistulas [64-66]. However, EAUS has several advantages over MRI in that it is portable and thus potentially available during fistula treatment in the operating room. EAUS-guided fistulography with contrast agents (e. g., hydrogen peroxide or SonoVue) is an accurate diagnostic modality in the preoperative assessment of anorectal fistulas $[67,68]$. Furthermore, MRI and EAUS are both superior to clinical examination for assessing treatment response or for detecting residual abscesses [69]. 3D EAUS may be helpful in preoperative risk stratification concerning incontinence in trans-sphincteric fistulas. 3D reconstruction thus allows preoperative risk stratification for incontinence in correlation to the length and location of the fistula $[70,71]$. EAUS can monitor the course of anal fistulas with a favorable impact on the outcome of surgical treatment for anal fistulas [72].

\section{Anal abscesses}

EAUS is recommended to assess perianal symptoms when abscesses or fistulas are suspected, as well as to monitor intersphincteric abscesses, which frequently have a benign and self-limiting course [73]. EAUS is also useful for delineating the origin of sepsis, thus supporting surgical and medical planning [74]. No comparative studies with a focus on EAUS and anal abscesses exist. However, the diagnostic performance is most probably similar to MRI. Furthermore, CT might have a role in this particular case [75].

Recommendation 9: EAUS is recommended for suspected anal fistulas and abscesses. LoE 2a, GoR B (For 15, Abstain 0, Against 0)

Recommendation 10: EAUS can be recommended to monitor the treatment of anal fistulas and/or anal abscess. LoE $2 \boldsymbol{b}$, GoR C (For 15, Abstain 0, Against 0)

\section{Anal incontinence}

EAUS is one of the techniques for sphincter evaluation in trauma-induced anal incontinence that most often is caused by obstetric injury [76]. Nevertheless, fecal incontinence must be evaluated in a multidisciplinary setting in consideration of clinical history, potential malignant or neurological diseases and pelvic insufficiency fractures. It is important to search for sphincter discontinuity and sphincter thinning and to perform perineal body measurement [77]. EAUS has been proven superior to digital anorectal examina- 

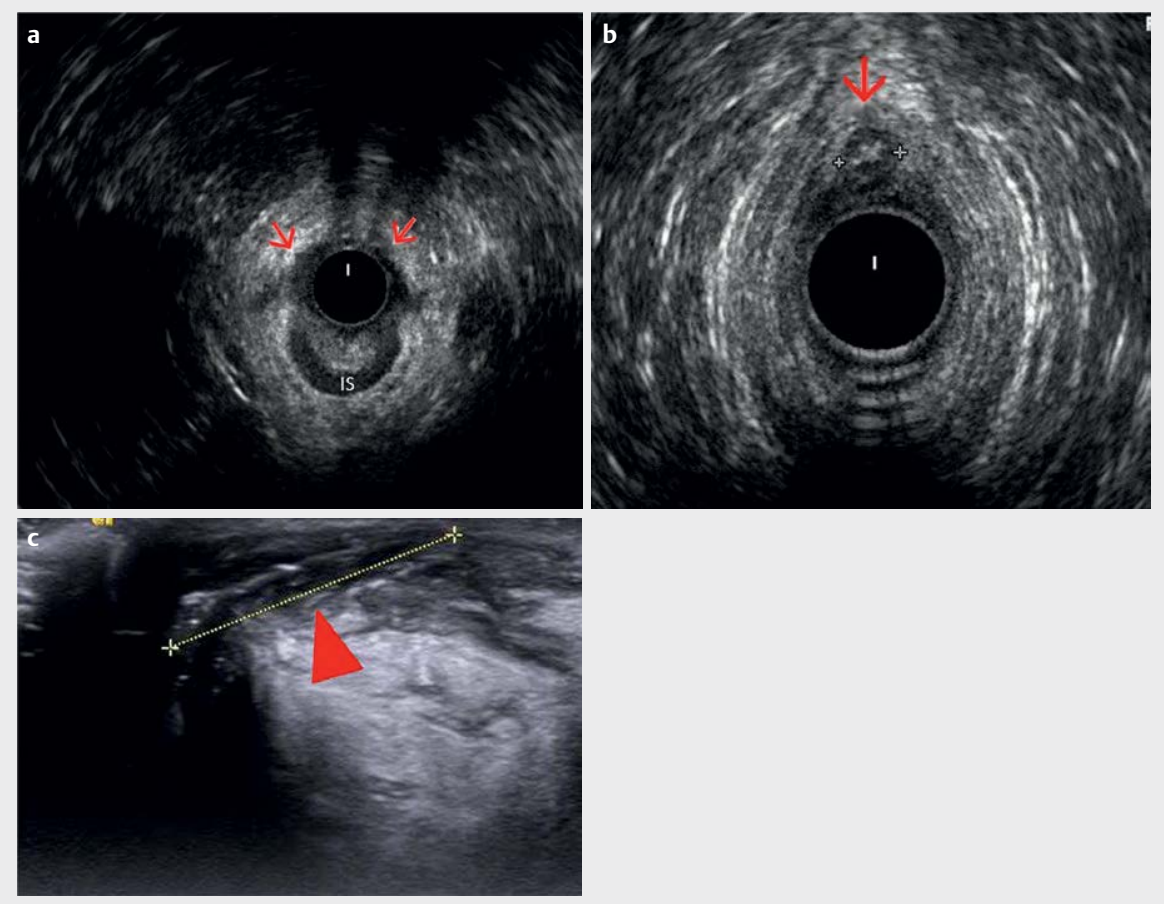

- Fig. 15 a Anterior half of internal sphincter (IS) defect (red arrows) visualized by radial endoanal ultrasound (EAUS). b Radial EAUS of an anteriorly located fistula (between calipers), with an endoanal image $\left(360^{\circ}\right)$ showing $120^{\prime}$ clock inter-sphincteric portion of the fistula (red arrow). c Perineal ultrasound (PNUS) view with a high frequency linear transducer depicts well the other portion of the fistula in between calipers (arrowhead), which is out of field of view for endoanal image (courtesy of Ismail Mihmanli).

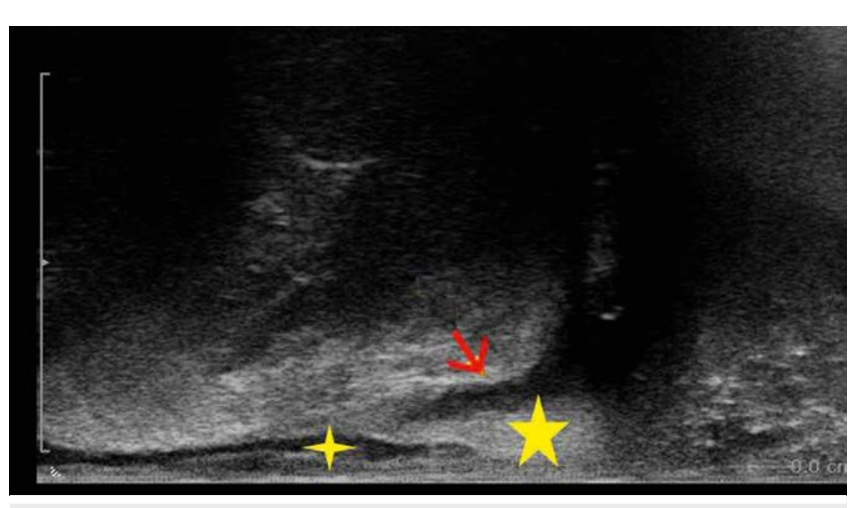

Fig. 16 Trans-sphincteric fistula (red arrow) visualized with linear EAUS, with the IAS and EAS marked by small and large stars, respectively (courtesy of Christian Nolsøe, Torben Lorentzen).

tion in 2 studies [77, 78]. EAUS has also been compared to endoanal MRI in several studies with minorly conflicting results. However, the overall impression is that the 2 techniques are equivalent in diagnosing EAS injury, while MRI is inferior for diagnosing IAS injury and superior for identifying EAS atrophy [79-82]. Levator hiatus can be measured by EAUS in the axial plane in both the antero-posterior diameter and area ( $>$ Fig. 17). These measurements can be predictive of prolapse and prolapse recurrence [83].

Recommendation 11: EAUS is recommended in patients with anal incontinence, especially in traumatic lesions. LoE $\mathbf{2 b}, \mathbf{G o R} \mathbf{C}$ (For 15, Abstain 0, Against 0)

\section{Diagnostic and therapeutic interventions}

EAUS-guided interventional procedures play a similarly important role in the diagnostic workup of anal carcinomas as well as in the clinical follow-up after radio-chemotherapy. If final diagnosis of a suspected anal carcinoma is not reached through surgical biopsy or if a suspicious mass seen either at clinical examination or in other imaging modalities during the course of follow-up cannot be diagnosed with conventional image-guided biopsy, US-guided biopsy is an obvious option. Unfortunately, the end-fire ultrasound probe and needle guide described above cannot be used for this purpose due to incongruence between the probe design and the very short and narrow anal canal. US-guided biopsy of anal or perianal masses can be performed accurately and safely using a dedicated endoanal transducer, with a linear array parallel to the long axis of the transducer ( $\triangleright$ Fig. 18ab). Using a free-hand technique whereby the needle is inserted transperineally, parallel to the probe long axis, all lesions in and around the anal canal can be biopsied and a final histological diagnosis can be reached. Only ERUS/EAUS can provide US-guided interventions as outlined herein. Surprisingly, to the best of our knowledge, series of either one of these techniques have not been published.

\section{Perineal Ultrasound}

\section{Anatomy and sonoanatomy}

Perineal ultrasound (PNUS) is used for the examination of the rectum and perianal region. The technique is easy and noninvasive and 
no special equipment is necessary. However, the procedure is not very popular yet and studies and publications are rare. The aim of this part is to describe the method and its options while also making it more popular $[84,85]$.

The PNUS technique requires knowledge of the anatomy and topography of the pelvic floor, the anal canal, distal rectum, sphincters and perianal and perirectal structures [86]. Detailed descriptions of the sonographic anatomy are given [87-91].

\section{Equipment and examination modalities}

Preparation:

The examination does not require specific preparation of the patient. A probe cover and ultrasound gel should be used for hygienic reasons and coupling of sonic signals [92].

Probes:

Conventional convex 3-5-MHz probes should be applied in the first step. The depth of acceptable view is $8-12 \mathrm{~cm}$. In the second

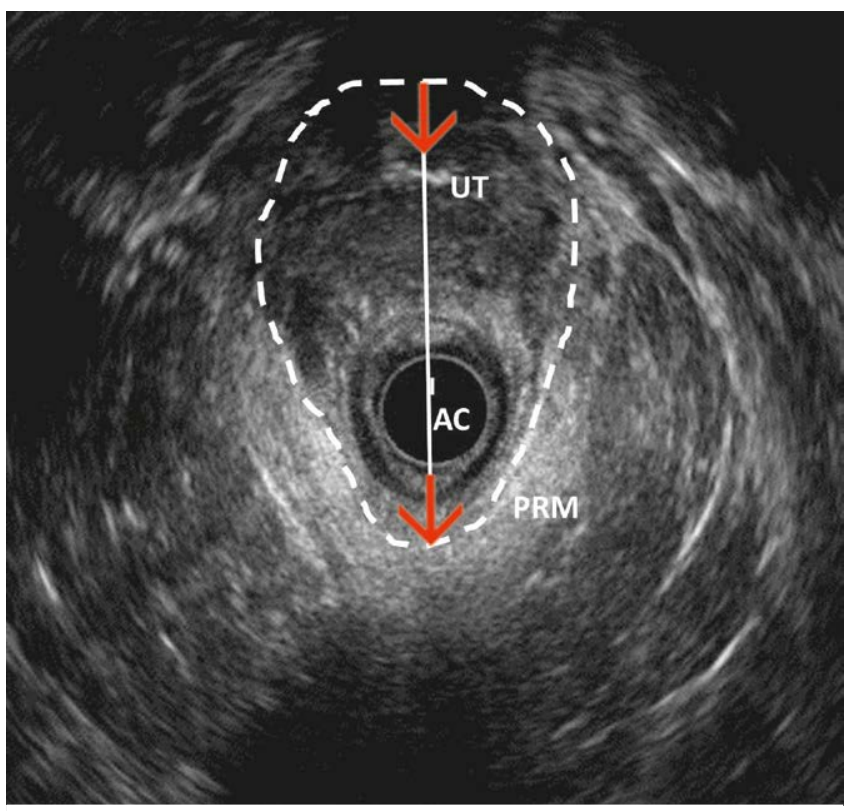

- Fig. 17 Endoanal two-dimensional axial ultrasound image of the levator hiatus, measured in terms of both area (dash lines) and antero-posterior diameter (red arrow). PRM: puborectal muscle; AC: anal canal; UT: lower level of uterus (courtesy of Ismail Mihmanli). step HF linear probes (7-15 or 4-9 MHz) should be used. The depth of scanning with the HF probe is $5-8 \mathrm{~cm}$. The HF probes can provide high-resolution imaging of the superficial structures in the perianal region and the perineum.

Examination position and technique:

The patient can be examined lying on the left side with bent legs and knees. Sometimes additional examinations can be performed in a dorsal/dorsosacral position in the knee-elbow position (KEP). Other authors performed PNUS in a dorsal (spinal) position (lithotomy position). For better orientation, the urinary bladder should be filled. Anatomical landmarks for the examination are the urinary bladder, symphysis, prostate/vagina, anal canal, internal and external anal sphincter, perianal fatty tissue and sacrum. In the longitudinal section, the urinary bladder is documented on the right side or on the lower side. Longitudinal scans are performed in the middle line (in continuity of the anal cleft to the symphysis). Transverse sections are documented like in ERUS sections ( $12 \mathrm{~h}$ ventral; $6 \mathrm{~h}$ dorsal; $9 \mathrm{~h}$ right; $3 \mathrm{~h} \mathrm{left}$ ). The perineum is delineated by the pubic symphysis and inferior pubic ligament (ventrally), the coccygeum and anococcygeal ligament (dorsally), the ischium (ventral lateral) and the sacrotuberous ligament (dorsal lateral). It is divided into anterior, central and posterior compartments [93].

PNUS should be combined with anorectal digital examination in order to obtain information about any painful points. In the presence of a fistula with a perianal cutaneous ostium, the ultrasound probe is applied in the direction of the fistula course. In the case of superficial abscesses, combination with digital palpation under ultrasound examination is useful. Lesion location should be described in relation to the sphincters.

Recommendation 12: PNUS can be particularly useful when ERUS/EAUS are not possible because of painful examination, lack of availability or after rectum resection (proctectomy or proctocolectomy). LoE 5, GoR C (For 15, Abstain 0, Against 0)

\section{Special techniques}

Color Doppler sonography is an inherent part of any investigation. It allows clarification of the vascular anatomy and architecture as well as better differentiation of neoplastic and inflammatory processes. Cross-sectional images provide better panoramic views and allow better $3 \mathrm{D}$ reconstruction than single ultrasound images [94].
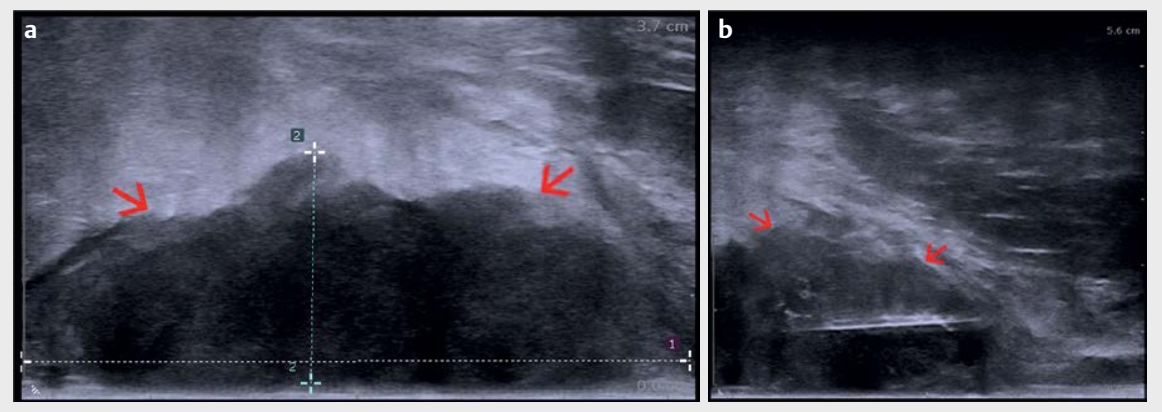

- Fig. 18 a Anal carcinoma visualized with a linear endoanal ultrasound (EAUS) probe as a hypoechoic tumor mass (red arrows). b Targeted EAUS Trucut biopsy of the anal carcinoma (red arrows) (courtesy of Christian Nolsøe, Torben Lorentzen). 

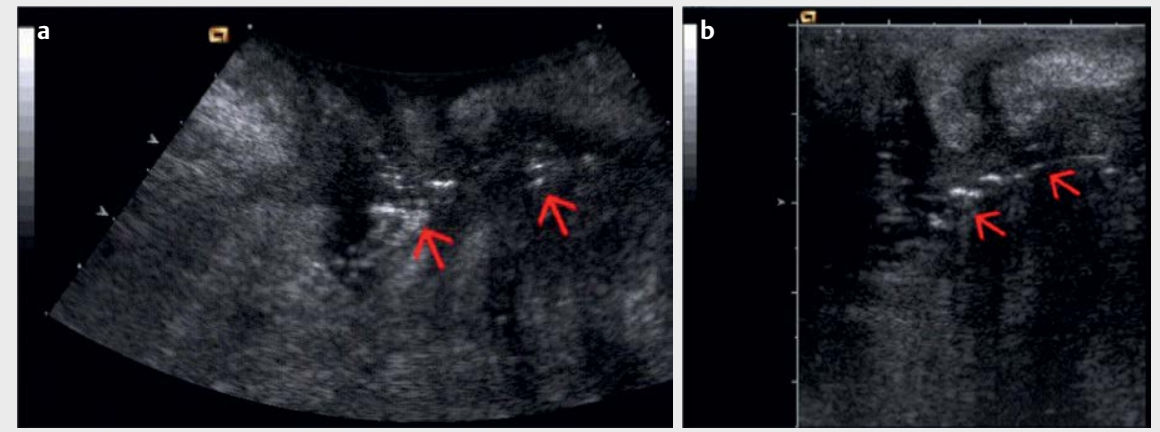

Fig. 19 a Rectovaginal fistula (arrow) in a Crohn's disease patient visualized by gas in the fistula (PNUS). b PNUS with a higher resolution by using a high frequency probe (courtesy of Dieter Nuernberg).

One way to visualize findings is the use of 3D sonography[9]. The pseudo-3D method, which applies defocusing of the acoustic lens and computational model assumptions, does not lead to substantial diagnostic improvement. In contrast, systematic 3D sonography applying matrix array technology leads to excellent image quality and valid volumetric measurements [95]. However, the disadvantage of this technique remains its limited availability and flexibility due to bulky ultrasound probes. The "free-hand" 3D method works with correlation algorithms and uses several sensor-supported steps (e. g., data acquisition, correlation algorithms and quantification of the data sets). This method is particularly useful for the evaluation of pelvic floor muscle dysfunction [96-101]. For the evaluation of rectal tumors, 3D data sets are recorded $[102,103]$.

Sclerosing fistulas show homogeneous stiff (harder) tissue structures in sono-elastography, whereas acute inflammation with perifocal edema is displayed as compressible (soft) tissue structures $[104,105]$.

With contrast-enhanced ultrasound (CEUS) it is possible to differentiate diffuse inflammatory diseases from abscesses. Thus, contrast-enhanced voiding urosonography allows the diagnosis and monitoring of the treatment of vesicoureteral reflux in pediatric patients as well as assessment of the urethra [106].

\section{Indications}

Indications for PNUS are anal and perianal pain, lesions of the entire perianal region and other perianal complaints (especially in children, in patients with venereal infections, HIV and IBD), suspicion and follow-up of fistulas and abscesses (especially in Crohn's disease), anal and rectal cancer (regional staging, evaluation of the sphincter apparatus and follow-up after rectal amputation), anal incontinence and some other indications in gynecology and urology (complementary sphincter evaluation, e. g., diagnosis of fistulas, sphincter tears, etc.) [107-109]. In children, it should be the first instrumental examination after inspection and digital anorectal palpation. It is also useful if clinical examination, ERUS/EAUS or MRI cannot be performed [110]. In complex questions concerning the perineum and the pelvis minor, MRI is the imaging method of choice. However, in acute inflammatory processes, especially in emergency situations, MRI is sometimes unavailable, time-con- suming and cost-intensive [111], and might be complemented by PNUS.

\section{Diagnosis of fistulas and abscesses}

Perianal fistulas and abscesses, together with suppurative hidradenitis and pilonidal sinus, represent the main cause of perianal sepsis [112]. Fistulas are of cryptoglandular origin (>90\%) and are less frequently Crohn's disease-related [113, 114]. At PNUS, fistulas appear as hypoechoic tracts, sometimes with gaseous artifacts within, between the anus or rectum and the perianal surface or vagina ( $>$ Fig. 19ab). Most of them have an irregular shape with a blind end or with connection to other organs like the uterus, urinary bladder, skin, or bowel. Differentiation of the fistulas is possible in superficial, inter-, trans-, extra- or supra-sphincteric types (Parks classification) [63]. Another classification based on anatomical and clinical parameters is the differentiation of fistulas as "simple" or "complex", according to the number and deep extension of fistulous tracks, the rectal inflammatory involvement and the association with anal stricture and abscesses [115].

Complex fistulas involving the EAS, levator and/or obturator muscles cannot be evaluated by PNUS alone. ERUS/EAUS and MRI examination should also be performed ( $\vee$ Fig. 15a-c, 20a-c). Due to its panoramic view, MRI can also be more accurate in this case. However, PNUS is a clinical examination method and the location of pain is helpful in therapy planning. Examination of the fistula track by PNUS, especially the detection of the internal opening, can be better performed by the injection of contrast agents (e. g., hydrogen peroxide or SonoVue) using a blunt cannula [92]. Several studies showed that PNUS has a high sensitivity and specificity in detecting perianal disease, comparable to those of MRI and ERUS/ EAUS [113, 116-118].

PNUS has high accuracy in detecting perianal fistulas and abscesses and can describe their anatomical relationship to the anal sphincters ( $>$ Fig. 21ab). A systematic review with meta-analysis (12 studies, 9 prospective) showed that PNUS has high sensitivity in detecting perianal fistulas (98.3\%) and their internal openings $(90.6 \%)$ and in classifying the fistulas (92.8\%), and that it is also accurate in detecting perianal abscesses (sensitivity $86.1 \%$ and PPV of $88.4 \%$ ) [119]. 

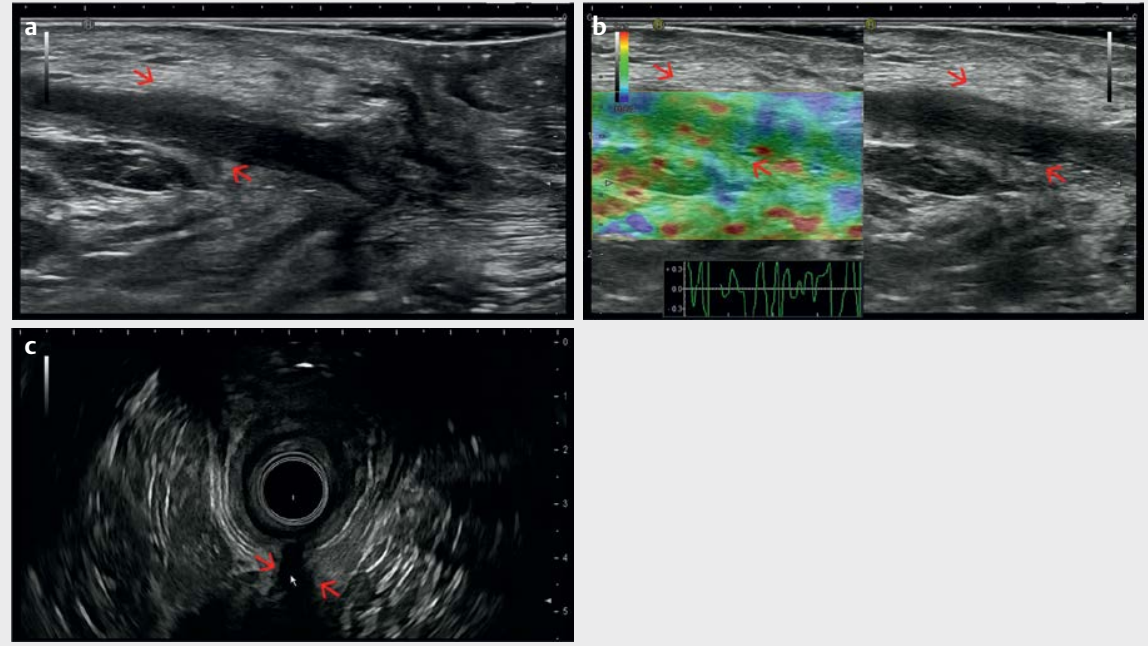

Fig. 20 a Trans-sphincteric fistula (red arrows) visualized with perineal ultrasound (PNUS) in the extrasphincteric course. b PNUS elastography showing the soft (compressible) fistula tract (red arrows). $\mathbf{c}$ Endoanal ultrasound (EAUS) appearance of the rest of the fistula tract (red arrow) (courtesy of Christoph F. Dietrich).
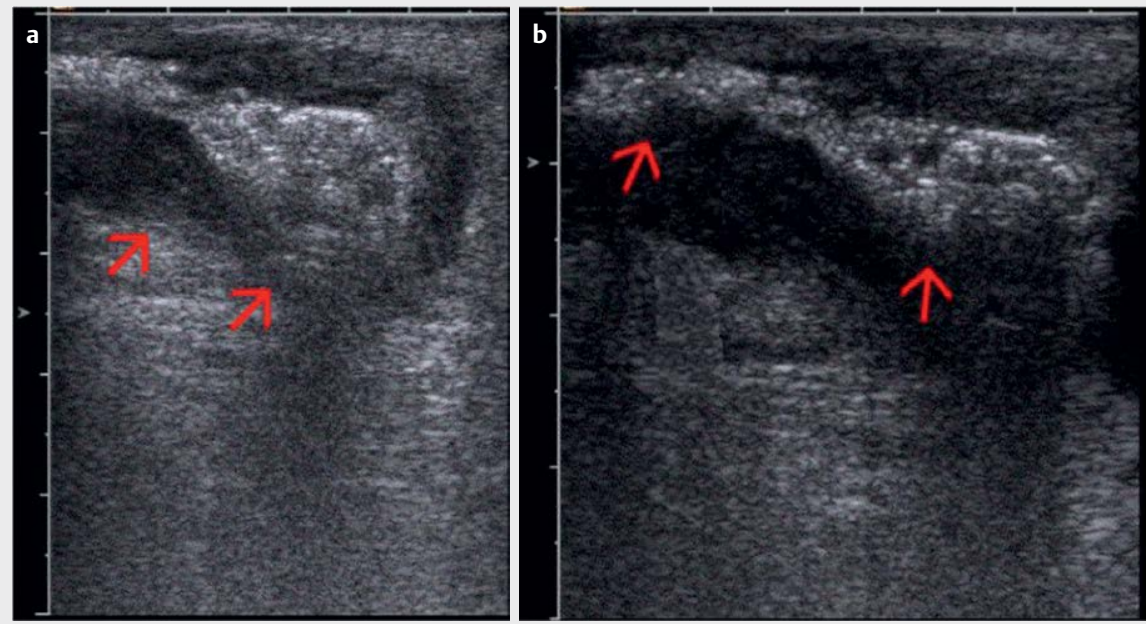

- Fig. 21 a Superficial perineal abscess with gas inside (red arrows) and echo-poor inflammatory surrounding (PNUS). b Fistula draining the abscess (red arrows) (courtesy of Dieter Nuernberg).

Several studies suggest that PNUS should be used as a preliminary tool in patients with suspected perianal fistulas and abscesses [120-123]. PNUS is also useful for monitoring patients with perianal fistulizing Crohn's disease under treatment with biologics. In particular, PNUS shows the persistence of fistulous tracks despite their clinical healing and closure of external opening after shortterm biological therapy. PNUS documentation could influence the duration of biological therapy [124].

PNUS can also be used to decide for interventional or surgical therapy and as a guidance method during interventions.

Recommendation 13: PNUS may be used as a tool in patients with suspected perianal inflammation, for the detection of perianal fistulas, their internal openings and relation with sphincters, as well as for the assessment of perianal abscesses and the monitoring of fistulas in Crohn's disease. LoE 1b, GoR B (For 13, Abstain 1, Against 1)

\section{Diagnosis of anal incontinence}

PNUS is also able to evaluate the sphincter apparatus and surroundings. The sonomorphological diagnosis of incontinence remains a domain of ERUS/EAUS, which gives a right-angled and orthogonal picture of both sphincters [125]. However, the examination of the sphincters by PNUS can give some additional information, especially in women, but it is limited by the diagonal angle of view. Combined results from ERUS/EAUS, PNUS and rectal manometry allow differentiation of 4 forms of anal incontinence: a purely sensory 


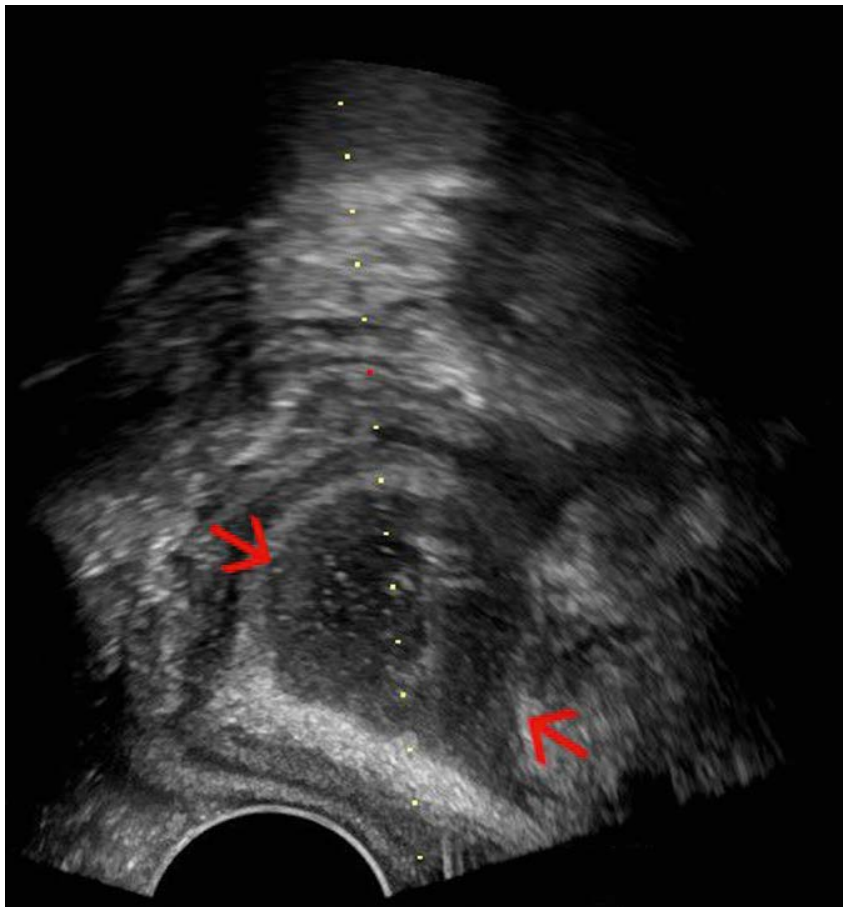

- Fig. 22 Anal abscess (red arrows) drained with a perineal ultrasound (PNUS) guided approach with an end-fire probe (courtesy of Christian Nolsøe, Torben Lorentzen).

form, a predominantly muscular form, a combination of both and a malfunction of the rectal reservoir function [126].

The most frequent causes of sphincter lesions in women are delivery traumas $[127,128]$. Resulting scars or defects are typically located between the ventral edge of the anus and the vagina. In the echo-rich EAS, the scar occurs as an echo-poor part. In the echo-poor IAS, the scar presents as an included echo-rich structure. Sonographic evidence of disruptions of the EAS correlates with fecal incontinence, particularly in women [129-137]. The complete evaluation of the sphincter apparatus for diagnosis of incontinence remains the domain of ERUS/EAUS. However, PNUS can give additional information on extra-sphincteric complications [138].

\section{Other indications}

PNUS can also give complementary information for the diagnosis of cervix insufficiency, uterine prolapse and secondary urinary incontinence. The ultrasound transducer is placed above the external aperture of the urethra in women, which allows imaging of the urethra and the posterior wall of the urinary bladder. The degree of uterine prolapse can be estimated from the delta angle between both structures at rest and during a Valsalva maneuver [139].

The classification of anorectal malformations is also possible $[140,141]$, which is of major importance in pediatrics. Also, PNUS can be very helpful for the diagnosis of anal atresia [142]. In daily practice, especially in stenosis, painful or limited ERUS/EAUS, PNUS is also used for the diagnosis, differentiation and staging of anal and rectal tumors. PNUS is also used for the aftercare of anal cancer patients and after rectum amputation. PNUS is still a method with limited published evidence for tumor assessment, even though it is of importance in daily practice.
Diagnostic and therapeutic interventions

A valuable extension of the diagnostic application of PNUS is its supportive role during invasive interventions, such as the drainage of liquids ( $\mathbf{F i g . ~ 2 2}$ ) or the targeted puncture of suspected tissue lesions. Specialized transducers with a built-in needle holder are available. However, conventional curved array probes can be used for free-hand puncture, particularly if the lesion of interest is close to the surface and large enough. An essential condition for interventions in the very sensitive perineal region is the appropriate use of local anesthesia [44, 143].

Recommendation 14: PNUS represents an effective guidance method for diagnostic and therapeutic interventions from the perineal side. LoE 3b, GoR B (For 15, Abstain 0, Against 0)

\section{Comparisons and combination of PNUS and ERUS}

For complementary information, PNUS should be followed by EAUS/ERUS. The methods use different angles of view. The advantages of PNUS are that it is readily available, is not painful, is associated with low costs, and is without complications. Furthermore, ERUS can fail to demonstrate perianal fistulas, especially when in a diagonal position with respect to the sphincter $[107,108]$. PNUS permits acquisition of images by using variable sections, especially in the oblique course of fistulas. However, as PNUS cannot demonstrate the complete sphincter, it is highly recommended to always use it in conjunction with ERUS [43].

PNUS can be performed after rectum amputation and in stenosis of the anal canal or inflammatory pain. US-guided interventions are usually safe and uncomplicated. PNUS with an HF probe seems to be more effective in superficial lesions. Nevertheless, ERUS is usually indicated in profound lesions (tumors, abscesses) [89].

Recommendation 15: PNUS may be recommended in combination with ERUS/EAUS if additional information is needed. LoE 5, GoR C (For 14, Abstain 1, Against 0)

\section{Conflict of Interest}

Representative: Conflict of Interest

Adrian Saftoiu: Speaker honoraria: Pentax Medical Singapore Ltd + Consulting / Advisory board: Mediglobe Corporation Gmbh; Dirk-André Clevert: Speaker honoraria: Bracco, Siemens, Philips, Samsung, GE, Falk + Board Member: Siemens, Philips, Samsung; Odd Helge Gilja: Speaker honoraria from the following companies: AbbVie, Bracco, Almirall, GE Healthcare, Takeda AS, Meda AS, Ferring AS and Allergan + Consultant fee for: Bracco, GE Healthcare, Takeda and Samsung; Christoph F Dietrich: Speaker honoraria: Bracco, Hitachi, GE, Mindray, Supersonic, Pentax, Olympus, Fuji, Boston Scientific, AbbVie, Falk Foundation, Novartis, Roche Advisory + Board Member: Hitachi, Mindray, Siemens + Research grant, GE, Mindray, SuperSonic; Giovanni Maconi: Speaker honoraria: Abbvie, Alfa Sigma, Janssen-Cilag + Advisory Board/Consultant fee, Allergan, Novartis, Takeda, THD; Dieter Nuernberg: Speaker honoraria: Falk Foundation + Research grant: GE Healthcare; Peter Vilmann: Speaker Honoraria: Pentax Medical Europe, Norgine + Consulting / Advisory board: Mediglobe Corporation Gmbh + Consulting: Boston Scientific; Eike Burmester: Speaker honoraria Hitachi Medical Systems, Olympus; The following members declared no conflicts of interest: Ana Barreiros, Elena Tatiana Ivan, Ismail Mihmanli, Christian Pallson Nolsoe, Frank Pfeffer, Søren R Rafaelsen, Jo E.R. Waage. 
[1] Kim M]. Transrectal ultrasonography of anorectal diseases: Advantages and disadvantages. Version 2. Ultrasonography 2015; 34 : 19-31

[2] Cârțână ET, Pârvu D, Săftoiu A. Endoscopic ultrasound: Current role and future perspectives in managing rectal cancer patients. J Gastrointestin Liver Dis 2011; 20: 407-413

[3] Kav T, Bayraktar Y. How useful is rectal endosonography in the staging of rectal cancer? World J Gastroenterol 2010; 16: 691-697

[4] Steele SR, Martin MJ, Place RJ. Flexible endorectal ultrasound for predicting pathologic stage of rectal cancers. Am J Surg 2002; 184 : 126-130

[5] Colaiácovo R, Assef MS, Ganc RL et al. Rectal cancer staging: Correlation between the evaluation with radial echoendoscope and rigid linear probe. Endosc Ultrasound 2014; 3: 161-166

[6] Fábián A, Bor R, Farkas K, Bálint A et al. Rectal tumor staging with endorectal ultrasound: Is there any difference between western and eastern european countries? Gastroenterol Res Pract 2016; 2016 : 8631381

[7] Ustundag Y, Fusaroli P. Are rigid probes sufficient to provide reliable data for rectal cancer staging? Endosc Ultrasound 2015; 4: 270

[8] Cârțână ET, Gheonea DI, Săftoiu A. Advances in endoscopic ultrasound imaging of colorectal diseases. World J Gastroenterol 2016; 22: 1756-1766

[9] Giovannini M, Ardizzone S. Anorectal ultrasound for neoplastic and inflammatory lesions. Best Pract Res Clin Gastroenterol 2006; 20: $113-135$

[10] Dietrich CF, Averkiou MA, Correas JM et al. An EFSUMB introduction into dynamic contrast-enhanced ultrasound (DCE-US) for quantification of tumor perfusion. Ultraschall Med 2012; 14: 344-351

[11] Piscaglia F, Nolsøe C, Dietrich CF et al. The EFSUMB guidelines and recommendations on the clinical practice of contrast Enhanced Ultrasound (CEUS): Update 2011 on non-hepatic applications. Ultraschall Med 2012; 33: 33-59

[12] Lu M, Yan B, Song J et al. Double-contrast-enhanced sonography for diagnosis of rectal lesions with pathologic correlation. J Ultrasound Med 2014; 33: 575-583

[13] Wang Y, Li L, Wang YX, Cui NY, Zou SM, Zhou CW et al. Time-intensity curve parameters in rectal cancer measured using endorectal ultrasonography with sterile coupling gels filling the rectum: Correlations with tumor angiogenesis and clinicopathological features. Biomed Res Int 2014; 2014: 587806

[14] Cartana ET, Gheonea DI, Cherciu IF et al. Assessing tumor angiogenesis in colorectal cancer by quantitative contrast-enhanced endoscopic ultrasound and molecular and immunohistochemical analysis. Endosc Ultrasound 2017 [Epub ahead of print]

[15] Bamber ], Cosgrove D, Dietrich CF et al. EFSUMB guidelines and recommendations on the clinical use of ultrasound elastography. Part 1: Basic principles and technology. Ultraschall in Med 2013; 34: 169-184

[16] Cosgrove D, Piscaglia F, Bamber ] et al. EFSUMB guidelines and recommendations on the clinical use of ultrasound elastography. Part 2: Clinical applications. Ultraschall in Med 2013; 34: 238-253

[17] Rafaelsen SR, Vagn-Hansen C, Sørensen T et al. Ultrasound elastography in patients with rectal cancer treated with chemoradiation. Eur J Radiol 2013; 82: 913-917

[18] Rafaelsen SR, Vagn-Hansen C, Sørensen T et al. Elastography and diffusion-weighted MRI in patients with rectal cancer. $\mathrm{Br}$ J Radiol 2015; 88: 20150294

[19] Waage JER, Havre RF, Leh S et al. Endorectal elastography in the evaluation of rectal tumors. Colorectal Dis 2011; 13: 1130-1137
[20] Waage JER, Rafaelsen SR, Borley NR et al. Strain Elastography Evaluation of Rectal Tumors: Inter- and Intraobserver Reproducibility. Ultraschall Med 2015; 36: 611-617

[21] Waage JER, Leh S, Røsler C et al. Endorectal ulstrasonography, strain elastography and MRI differentiation of rectal adenomas and adenocarcinomas. Colorectal Dis 2015; 17: 124-131

[22] Waage JER, Bach SP, Pfeffer F et al. Combined endorectal ultrasonography and strain elastography for the staging of early rectal cancer. Colorectal Dis 2015; 17: 50-56

[23] Amin MB, Edge S, Greene F, Byrd DR, Brookland RK, Washington MK et al. AJCC Cancer Staging Manual. $8^{\text {th }}$ Edition Springer International Publishing; 2017

[24] Beets-Tan RGH, Lambregts DMJ, Maas M et al. Magnetic resonance imaging for clinical management of rectal cancer: Updated recommendations from the 2016 European Society of Gastrointestinal and Abdominal Radiology (ESGAR) consensus meeting. Eur Radiol 2018; 28: 1465-1475

[25] Puli SR, Bechtold ML, Reddy JB, Choudhary A, Antillon MR, Brugge WR. How good is endoscopic ultrasound in differentiating various T stages of rectal cancer? Meta-analysis and systematic review. Ann Surg Oncol 2009; 16: 254-265

[26] Zhou Y, Shao W, Lu W. Diagnostic value of endorectal ultrasonography for rectal carcinoma: A meta-analysis. J Can Res Ther 2014; 10 : 319-322

[27] Fernandez-Esparrach G, Ayuso-Colella JR, Sendino O et al. EUS and magnetic resonance imaging in the staging of rectal cancer: A prospective and comparative study. Gastrointest Endosc 2011; 74: 347-354

[28] Puli SR, Bechtold ML, Reddy JB et al. Can endoscopic ultrasound predict early rectal cancers that can be resected endoscopically? A meta-analysis and systematic review. Dig Dis Sci 2010; 55 : 1221-1229

[29] Zorcolo L, Fantola G, Cabras F et al. Preoperative staging of patients with rectal tumors suitable for transanal endoscopic microsurgery (TEM): Comparison of endorectal ultrasound and histopathologic findings. Surg Endosc 2009; 23: 1384-1389

[30] Glancy DG, Pullyblank AM, Thomas MG. The role of colonoscopic endoanal ultrasound scanning (EUS) in selecting patients suitable for resection by transanal endoscopic microsurgery (TEM). Colorectal Dis 2005; 7: 148-150

[31] Carmody BJ, Otchy DP. Learning curve of transrectal ultrasound. Dis Colon Rectum 2000; 43: 193-197

[32] Rafaelsen SR, Sorensen T, Jakobsen A et al. Transrectal ultrasonography and magnetic resonance imaging in the staging of rectal cancer. Effect of experience. Scand J Gastroenterol 2008; 43: 440-446

[33] Morris OJ, Draganic B, Smith S. Does a learning curve exist in endorectal two-dimensional ultrasound accuracy? Tech Coloproctol 2011; 15: 301-311

[34] Marusch F, Ptok H, Sahm M et al. Endorectal ultrasound in rectal carcinoma - do the literature results really correspond to the realities of routine clinical care? Endoscopy 2011; 43: 425-431

[35] Rafaelsen SR, Kronborg O, Fenger C. Echo pattern of lymph nodes in colorectal cancer: An in vitro study. Br J Radiol 1992; 65: 218-220

[36] Puli SR, Reddy JB, Bechtold ML et al. Accuracy of endoscopic ultrasound to diagnose nodal invasion by rectal cancers: A metaanalysis and systematic review. Ann Surg Oncol 2009; 16: 1255-1265

[37] Li L, Chen S, Wang K et al. Diagnostic value of endorectal ultrasound in preoperative assessment of lymph node involvement in colorectal cancer: A meta-analysis. Asian Pac J Cancer Prev 2015; 16: 3485-3491

[38] Li XT, Sun YS, Tang L et al. Evaluating local lymph node metastasis with magnetic resonance imaging, endoluminal ultrasound and computed tomography in rectal cancer: A meta-analysis. Colorectal Dis 2015; 17: 0129-0135 
[39] Fernández-Esparrach G, Alberghina N, Subtil JC et al. Endoscopic ultrasound-guided fine needle aspiration is highly accurate for the diagnosis of perirectal recurrence of colorectal cancer. Dis Colon Rectum 2015; 58: 469-473

[40] Dumonceau JM, Polkowski M, Larghi A et al. Indications, results, and clinical impact of endoscopic ultrasound (EUS)-guided sampling in gastroenterology: European Society of Gastrointestinal Endoscopy (ESGE) Clinical Guideline. Endoscopy 2011; 43: 897-912

[41] Marone P, de Bellis M, Avallone A et al. Accuracy of endoscopic ultrasound in staging and restaging patients with locally advanced rectal cancer undergoing neoadjuvant chemoradiation. Clin Res Hepatol Gastroenterol 2011; 35: 666-670

[42] Memon S, Lynch AC, Bressel M et al. Systematic review and meta-analysis of the accuracy of MRI and endorectal ultrasound in the restaging and response assessment of rectal cancer following neoadjuvant therapy. Colorectal Dis 2015; 17: 748-761

[43] Mihmanli I, Kantarci F, Dogra VS. Endoanorectal Ultrasonography. Ultrasound Quarterly 2011; 27: 87-104

[44] Lorentzen T, Nolsoe C, Skjoldbye B. Ultrasound-guided drainage of deep pelvic abscesses: Experience with 33 cases. Ultrasound in medicine \& biology 2011; 37: 723-728

[45] Christensen AF, Nielsen MB, Engelholm SA, Roed H, Svendsen LB, Christensen $\mathrm{H}$. Three-dimensional anal endosonography may improve staging of anal cancer compared with two-dimensional endosonography. Dis Colon Rectum 2004; 47: 341-345

[46] Christensen AF, Nyhuus B, Nielsen MB. Interobserver and intraobserver variation of two-dimensional and three-dimensional anal endosonography in the evaluation of recurrent anal cancer. Dis Colon Rectum 2009; 52: 484-488

[47] Pezim ME, Spencer RJ, Stanhope CR et al. Sphincter repair for fecal incontinence after obstetrical or iatrogenic injury. Dis Colon Rectum 1987; 30: 521-525

[48] Glynne-Jones R, Nilsson PJ, Aschele C et al. Anal cancer: ESMO-ESSO-ESTRO clinical practice guidelines for diagnosis, treatment and follow-up. European journal of surgical oncology: The journal of the European Society of Surgical Oncology and the British Association of Surgical Oncology 2014; 40: 1165-1176

[49] Jacopo M. EAUS for anal cancer staging. International Journal of Colorectal Disease 2011; 26: 385-386

[50] Martellucci ], Naldini G, Colosimo C et al. Accuracy of EAUS in the follow-up assessment for squamous cell carcinoma of the anal canal treated with radiochemotherapy. Surgical Endoscopy 2009; 23: 1054-1057

[51] Otto SD, Lee L, Buhr H] et al. Staging anal cancer: Prospective comparison of transanal endoscopic ultrasound and magnetic resonance imaging. Journal of gastrointestinal surgery: Official Journal of the Society for Surgery of the Alimentary Tract 2009; 13: 1292-1298

[52] Parikh J, Shaw A, Grant LA et al. Anal carcinomas: The role of EAUS and magnetic resonance imaging in staging, response evaluation and follow-up. European Radiology 2011; 21: 776-785

[53] Tarantino D, Bernstein MA. EAUS in the staging and management of squamous-cell carcinoma of the anal canal: Potential implications of a new ultrasound staging system. Diseases of the Colon and Rectum 2002; 45: 16-22

[54] Drudi FM, Raffetto N, De Rubeis M et al. ERUS staging and follow-up in patients with anal canal cancer. La Radiologia Medica 2003; 106: 329-337

[55] Giovannini M, Bardou V], Barclay R et al. Anal carcinoma: Prognostic value of endorectal ultrasound (ERUS). Results of a prospective multicenter study. Endoscopy 2001; 33: 231-236

[56] Sirikurnpiboon S, Phadhana-anake O, Awapittaya B. Comparison of Endoanal Ultrasound with Clinical Diagnosis in Anal Fistula Assessment. J Med Assoc Thai 2016; 99: (Suppl 2): S69-S74
[57] Toyonaga T, Tanaka Y, Song JF, Katori R et al. Comparison of accuracy of physical examination and endoanal ultrasonography for preoperative assessment in patients with acute and chronic anal fistula. Tech Coloproctol 2008; 12: 217-223

[58] Wiese DM, Beaulieu D, Slaughter JC et al. Use of endoscopic ultrasound to guide adalimumab treatment in perianal crohn's disease results in faster fistula healing. Inflamm Bowel Dis 2015; 21: 1594-1599

[59] Spradlin NM, Wise PE, Herline A] et al. A randomized prospective trial of endoscopic ultrasound to guide combination medical and surgical treatment for Crohn's perianal fistulas. Am J Gastroenterol 2008; 103: 2527-2535

[60] Schwartz DA, White CM, Wise PE, Herline AJ. Use of endoscopic ultrasound to guide combination medical and surgical therapy for patients with Crohn's perianal fistulas. Inflamm Bowel Dis 2005; 11: 727-732

[61] Ardizzone S, Maconi G, Colombo E et al. Perianal fistulae following infliximab treatment: Clinical and endosonographic outcome. Inflamm Bowel Dis 2004; 10: 91-96

[62] Lahat A, Assulin Y, Beer-Gabel M et al. Endoscopic ultrasound for perianal Crohn's disease: Disease and fistula characteristics, and impact on therapy. J Crohns Colitis 2012; 6: 311-316

[63] Parks AG, Gordon PH, Hardcastle JD. A classification of fistula-in-ano. Br J Surg 1976; 63: 1-12

[64] Alabiso ME, lasiello F, Pellino G et al. 3D-EAUS and MRI in the Activity of Anal Fistulas in Crohn's Disease. Gastroenterol Res Pract 2016; 2016: 1895694

[65] Siddiqui MR, Ashrafian H, Tozer P et al. A diagnostic accuracy meta-analysis of endoanal ultrasound and MRI for perianal fistula assessment. Dis Colon Rectum 2012; 55: 576-585

[66] Gustafsson UM, Kahvecioglu B, Aström G et al. Endoanal ultrasound or magnetic resonance imaging for preoperative assessment of anal fistula: A comparative study. Colorectal Dis 2001; 3: 189-197

[67] Tepes B, Cerni I. The use of different diagnostic modalities in diagnosing fistula-in-ano. Hepatogastroenterology 2008; 55 : 912-915

[68] Tsankov T, Tankova L, Deredjan $\mathrm{H}$ et al. Contrast-enhanced endoanal and transperineal sonography in perianal fistulas. Hepatogastroenterology 2008; 55: 13-16

[69] Panes J, Bouhnik $Y$, Reinisch W et al. Imaging techniques for assessment of inflammatory bowel disease: Joint ECCO and ESGAR evidence-based consensus guidelines. J Crohns Colitis 2013; 7: 556-585

[70] Murad-Regadas SM, Regadas FS, Rodrigues LV et al. The role of 3-dimensional anorectal ultrasonography in the assessment of anterior trans-sphincteric fistula. Dis Colon Rectum 2010; 53: 1035-1040

[71] Garcés-Albir M, García-Botello SA, Esclapez-Valero P et al. Quantifying the extent of fistulotomy. How much sphincter can we safely divide? A three-dimensional endosonographic study. Int J Colorectal Dis 2012; 27: 1109-1116

[72] Ding JH, Bi LX, Zhao K et al. Impact of three-dimensional endoanal ultrasound on the outcome of anal fistula surgery: A prospective cohort study. Colorectal Dis 2015; 17: 1104-1112

[73] Viganò C, Losco A, Caprioli F et al. Incidence and clinical outcomes of intersphincteric abscesses diagnosed by anal ultrasonography in patients with Crohn's disease. Inflamm Bowel Dis 2011; 17: 2102-2108

[74] Brillantino A, lacobellis F, Di Sarno G et al. Role of tridimensional endoanal ultrasound (3D-EAUS) in the preoperative assessment of perianal sepsis. Int J Colorectal Dis 2015; 30: 535-542

[75] Khati N], Sondel Lewis N, Frazier AA et al. CT of acute perianal abscesses and infected fistulae: A pictorial essay. Emerg Radiol 2015; 22: 329-335 
[76] Albuquerque A. Endoanal ultrasonography in fecal incontinence: Current and future perspectives. World J Gastrointest Endosc 2015; 7: 575-581

[77] Sultan AH, Kamm MA, Talbot IC et al. Anal endosonography for identifying external sphincter defects confirmed histologically. $\mathrm{Br}$ ] Surg 1994; 81: 463-465

[78] Jeppson PC, Paraiso MF, Jelovsek JE et al. Accuracy of the digital anal examination in women with fecal incontinence. Int Urogynecol ] 2012; 23: 765-768

[79] Malouf AJ, Williams AB, Halligan S et al. Prospective assessment of accuracy of endoanal MR imaging and endosonography in patients with fecal incontinence. AJR Am J Roentgenol 2000; 175: 741-745

[80] Dobben AC, Terra MP, Slors JF et al. External anal sphincter defects in patients with fecal incontinence: Comparison of endoanal MR imaging and endoanal US. Radiology 2007; 242: 463-471

[81] West RL, Dwarkasing S, Briel JW et al. Can three-dimensional endoanal ultrasonography detect external anal sphincter atrophy? A comparison with endoanal magnetic resonance imaging. Int ] Colorectal Dis 2005; 20: 328-333

[82] Cazemier M, Terra MP, Stoker ] et al. Atrophy and defects detection of the external anal sphincter: Comparison between three-dimensional anal endosonography and endoanal magnetic resonance imaging. Dis Colon Rectum 2006; 49: 20-27

[83] Dietz HP. Pelvic floor ultrasound: A review. Am J Obstet and Gynecol 2010; 202: 321-334

[84] Nuernberg D. Perineale Sonographie. In Kursbuch., (Hrsg.). Dietrich CF. Dt. Ärzteverlag; 2019, in press

[85] Simanowski JH. Perineal ultrasonography of anal and low rectal illnesses - meaningful instrument in the clinical everyday life. Ultraschall Med 2004; 25: 108-110

[86] Rubens DJ, Strang JG, Bogineni-Misra S et al. Transperineal sonography of the rectum: Anatomy and pathology revealed by sonography compared with CT and MR imaging. AJR Am J Roentgenol 1998; 170: 637-642

[87] Dietrich CF, Allgayer H, Müller G, Paolucci V. Anorektale (ARUS) und endorektale (ERUS) Endosonographie. In: Dietrich CF. (editor.) Endoskopischer Ultraschall - Eine Einführung. Konstanz: Schnetztor Verlag; 2005: 294-315

[88] Dietrich CF. Endoscopic ultrasound. An introduction. Thieme Verlag; 2006

[89] Sailer M, Allgayer H, Dietrich CF. Endoanale und endorektale Sonographie. In: Dietrich CF. (editor). Endosonographie. Stuttgart: Thieme Verlag; 2008: 390-413

[90] Dietrich CF, Barreiros AP, Nuernberg D et al. Perianal ultrasound. Z Gastroenterol 2008; 46: 625-630

[91] Han TI, Kim IO, Kim WS et al. ultrasound identification of the anal sphincter complex and levator ani muscle in neonates: Infracoccygeal approach. Radiology 2000; 217: 392-394

[92] Merz E. Transducer hygiene - an underrated topic? Ultraschall Med 2005; $26: 7-8$

[93] Albuquerque A, Pereira E. Current applications of transperineal ultrasound in gastroenterology. World J Radiol 2016; 8: 370-377

[94] Mallouhi A, Bonatti H, Peer S et al. Detection and characterization of perianal inflammatory disease: Accuracy of transperineal combined gray scale and color Doppler sonography. J Ultrasound Med 2004; 23: 19-27

[95] Pistor G. Sonographic visualization of the axial level of the anal sphincters. Preliminary results in children. Ultraschall Med 2003; 24: 250-254

[96] Jurgens J. Perineal sonography: Using time modulated 2D-ultrasound in a freehand 3D technique. Ultraschall Med 2004; 25: 54-57

[97] García Mejido JA, Suárez Serrano CM, Fernández Palacín A et al. Evaluation of levator ani muscle throughout the different stages of labor by transperineal 3D ultrasound. Neurourol Urodyn 2017; 36: 1776-1781
[98] Raimondo D, Youssef A, Mabrouk M et al. Pelvic floor muscle dysfunction at 3D/4D transperinal ultrasound in patients with deep infiltrating endometriosis: A pilot study. Ultrasound Obstet Gynecol 2017; 50: 527-532

[99] Dietz HP, Steensma AB. Posterior compartment prolapse on two-dimensional and three-dimensional pelvic floor ultrasound: The distinction between true rectocele, perineal hypermobility and enterocele. Ultrasound Obstet Gynecol 2005; 26: 73-77

[100] Kołodziejczak M, Santoro GA, Słapa RZ et al. Usefulness of 3D transperineal ultrasound in severe stenosis of the anal canal: Preliminary experience in four cases. Tech Coloproctol 2014; 18: 495-501

[101] Oom DM, West RL, Schouten WR et al. Detection of anal sphincter defects in female patients with fecal incontinence: A comparison of 3-dimensional transperineal ultrasound and 2-dimensional endoanal ultrasound. Dis Colon Rectum 2012; 55: 646-652

[102] Onik G, Barzell W. Transperineal 3D mapping biopsy of the prostate: An essential tool in selecting patients for focal prostate cancer therapy. Urol Oncol 2008; 26: 506-510

[103] Huang WC, Yang SH, Yang JM. Three-dimensional transperineal sonographic characteristics of the anal sphincter complex in nulliparous women. Ultrasound Obstet Gynecol 2007; 30: 210-220

[104] Dietrich CF. Anorectal endosonography. Elastography Medix 2008; (Supplement): 54-57

[105] Allgayer H, Ignee A, Dietrich CF. Endosonographic elastography of the anal sphincter in patients with fecal incontinence. Scand ] Gastroenterol 2010; 45: 30-38

[106] Woźniak MM, Pawelec A, Wieczorek AP et al. 2D/3D/4D contrast-en hanced voiding urosonography in the diagnosis and monitoring of treatment of vesicoureteral reflux in children - can it replace voiding cystourethrography? J Ultrason 2013; 13: 394-407

[107] Bonatti H, Lugger $P$, Hechenleitner $P$ et al. Transperineal sonography in anorectal disorders. Ultraschall Med 2004; 25: 111-115

[108] Stewart LK, McGee J, Wilson SR. Transperineal and transvaginal sonography of perianal inflammatory disease. AJR Am J Roentgenol 2001: 177: 627-632

[109] Barreiros AP, Hirche TO, Ignee A et al. Indications and limitations of perineal ultrasound examination. Scand J Gastroenterol 2010; 45: 764-765

[110] Magdeburg B, Fried M, Meyenberger C. Endoscopic ultrasonography in the diagnosis, staging, and follow-up of anal carcinomas. Endoscopy 1999; 31: 359-364

[111] Morris J, Spencer JA, Ambrose NS. MR imaging classification of perianal fistulas and its implications for patient management. Radiographics 2000; 20: 623-635

[112] Sainio P. Fistula-in-ano in a defined population. Incidence and epidemiological aspects. Ann Chir Gynaecol 1984; 73: 219-224

[113] Wedemeyer ], Kirchhoff T, Manns MP, Gebel M], Bleck JS. Transcutaneous perianal ultrasound (PAUS) for the imaging of fistulas and abscesses in Crohn's disease. Z Gastroenterol 2004; 42: 1315-1320

[114] Caprioli F, Losco A, Vigano C, Conte D, Biondetti P, Forzenigo LV et al. Computer-assisted evaluation of perianal fistula activity by means of anal ultrasound in patients with Crohn's disease. Am J Gastroenterol 2006; 101: 1551-1558

[115] American Gastroenterological Association Clinical Practice Committee. American Gastroenterological Association medical position statement: Perianal Crohn's disease. Gastroenterology 2003; 125: $1503-1507$

[116] Maconi G, Ardizzone S, Greco S et al. Transperineal ultrasound in the detection of perianal and rectovaginal fistulae in Crohn's disease. Am J Gastroenterol 2007; 102: 2214-2219

[117] Maconi G, Tonolini M, Monteleone M et al. Transperineal perineal ultrasound versus magnetic resonance imaging in the assessment of perianal Crohn's disease. Inflamm Bowel Dis 2013; 19: 2737-2743 
[118] Hwang JY, Yoon HK, Kim WK et al. Transperineal ultrasonography for evaluation of the perianal fistula and abscess in pediatric Crohn disease: Preliminary study. Ultrasonography 2014; 33: 184-190

[119] Maconi G, Greco MT, Asthana AK. Transperineal Ultrasound for Perianal Fistulas and Abscesses - A Systematic Review and MetaAnalysis. Ultraschall Med 2017; 38: 265-272

[120] Terracciano F, Scalisi G, Bossa F et al. Transperineal ultrasonography: First level exam in IBD patients with perianal disease. Dig Liver Dis 2016; 48: 874-879

[121] Bor R, Farkas K, Bálint A, Szűcs M, Ábrahám S, Milassin Á et al. Prospective comparison of magnetic resonance imaging, transrecta and transperineal sonography, and surgical findings in complicated perianal crohn disease. J Ultrasound Med 2016; 35: 2367-2372

[122] Wright EK, Novak KL, Lu C, Panaccione R, Ghosh S, Wilson SR. Transperineal ultrasonography in perianal Crohn disease: A valuable imaging modality. Can J Gastroenterol Hepatol 2015; 29: 445-447

[123] Bezzio C, Bryant RV, Manes $G$ et al. New horizons in the imaging of perianal Crohn's disease: Transperineal ultrasonography. Expert Rev Gastroenterol Hepatol 2017; 28: 1-8

[124] Rasul I, WIson SR, MacRae H et al. Clinical and radiological response after Infliximab treatment for perianal fistulizing Crohn's disease. Am J Gastroenterol 2003; 99: 82-88

[125] Bartram Cl, Sultan AH. Anal endosonography in faecal incontinence. Gut 1995; 37: 4-6

[126] Bordeianou L, Lee KY, Rockwood T et al. Anal resting pressures at manometry correlate with the Fecal Incontinence Severity Index and with presence of sphincter defects on ultrasound. Dis Colon Rectum 2008; 51: 1010-1014

[127] Andrews V, Sultan AH, Thakar R et al. Occult anal sphincter injuries - myth or reality? BJOG 2006; 113: 195-200

[128] Wheeler TL, Richter HE. Delivery method, anal sphincter tears and fecal incontinence: New information on a persistent problem. Curr Opin Obstet Gynecol 2007; 19: 474-479

[129] Saranovic D, Krivokapic Z, Masulovic D et al. Endoanal ultrasonography in establishing the diagnosis of fecal incontinence. Acta Chir lugosl 2007; 54: 159-162

[130] Beer-Gabel M, Assoulin Y, Amitai M et al. A comparison of dynamic transperineal ultrasound (DTP-US) with dynamic evacuation proctography (DEP) in the diagnosis of cul de sac hernia (enterocele) in patients with evacuatory dysfunction. Int J Colorectal Dis 2008; 23: 513-519
[131] Cornelia L, Stephan B, Michel B, Antoine W, Felix K. Trans-perineal versus endo-anal ultrasound in the detection of anal sphincter tears. Eur J Obstet Gynecol Reprod Biol 2002; 103: 79-82

[132] Martellucci J, Naldini G. Clinical relevance of transperineal ultrasound compared with evacuation proctography for the evaluation of patients with obstructed defaecation. Colorectal Dis 2011; 13: 1167-1172

[133] Roos AM, Abdool Z, Sultan AH, Thakar R. The diagnostic accuracy of endovaginal and transperineal ultrasound for detecting anal sphincter defects: The PREDICT study. Clin Radiol 2011; 66: 597-604

[134] Son JK, Taylor GA. Transperineal ultrasonography. Pediatr Radiol 2014; 44: 193-201

[135] Shek KL, Guzman-Rojas R, Dietz HP. Residual defects of the external anal sphincter following primary repair: An observational study using transperineal ultrasound. Ultrasound Obstet Gynecol 2014; 44: 704-709

[136] Valsky DV, Cohen SM, Lipschuetz M et al. Three-dimensional transperineal ultrasound findings associated with anal incontinence after intrapartum sphincter tears in primiparous women. Ultrasound Obstet Gynecol 2012; 39: 83-90

[137] Weemhoff M, Kluivers KB, Govaert B et al. Transperineal ultrasound compared to evacuation proctography for diagnosing enteroceles and intussusceptions. Int J Colorectal Dis 2013; 28: 359-363

[138] Roche B, Deleaval J, Fransioli A et al. Comparison of transanal and external perineal ultrasonography. Eur Radiol 2001; 11: 1165-1170

[139] Bader W, Tunn R, Viereck V et al. Introital and perineal sonography in diagnosing stress urinary incontinence - possible clinical applications. Ultraschall Med 2004; 25: 181-190

[140] Han TI, Kim IO, Kim WS. Imperforate anus: Ultrasound determination of the type with infracoccygeal approach. Radiology 2003; 228: 226-229

[141] Kim IO, Han TI, Kim WS et al. Transperineal ultrasonography in imperforate anus: Identification of the internal fistula. J Ultrasound Med 2000; 19: 211-216

[142] Zbar AP, Murison R. Transperineal ultrasound in the assessment of haemorrhoids and haemorrhoidectomy: A pilot study. Tech Coloproctol 2010; 14: 175-179

[143] Sperling DC, Needleman L, Eschelman D] et al. Deep pelvic abscesses: Transperineal US-guided drainage. Radiology 1998; 208: 111-115 